\title{
Operational Considerations regarding On-Demand Air Mobility: A Literature Review and Research Challenges
}

\author{
Xiaoqian Sun $\mathbb{D}^{1,2}$, Sebastian Wandelt $\mathbb{D}^{1,},{ }^{1,2}$ Michael Husemann, ${ }^{3}$ and Eike Stumpf ${ }^{3}$ \\ ${ }^{1}$ School of Electronic and Information Engineering, Beihang University, 100191 Beijing, China \\ ${ }^{2}$ National Engineering Laboratory for Multi-Modal Transportation Big Data, 100191 Beijing, China \\ ${ }^{3}$ Institute of Aerospace Systems, RWTH Aachen University, 52062 Aachen, Germany \\ Correspondence should be addressed to Sebastian Wandelt; wandelt@informatik.hu-berlin.de
}

Received 8 September 2019; Revised 25 November 2020; Accepted 22 January 2021; Published 5 February 2021

Academic Editor: Dongjoo Park

Copyright (c) 2021 Xiaoqian Sun et al. This is an open access article distributed under the Creative Commons Attribution License, which permits unrestricted use, distribution, and reproduction in any medium, provided the original work is properly cited.

\begin{abstract}
The idea and development of on-demand air mobility (ODAM) services are revolutionizing our urban/regional transportation sector by exploring the third dimension: vertical airspace. The fundamental concept of on-demand air taxi operations is not new, but advances in aircraft design and battery/engine technology plus massive problems with congestion and increased travel demands around the world have recently led to a large number of studies which aim to explore the potential benefits of ODAM. Unfortunately, given the lack of an established, formal problem definition, missing reference nomenclature for ODAM research, and a multitude of publication venues, the research development is not focused and, thus, does not tap the full potential of the workforce engaged in this topic. This study synthesizes the recently published literature on operational aspects of ODAM. Our contribution consists of two major parts. The first part dissects previous studies and performs cross-comparison of report results. We cover five main categories: demand estimation methodology, infrastructure/port design/location problem, operational planning problem, operational constraints' identification, and competitiveness with other transportation modes. The second part complements the report of aggregated findings by proposing a list of challenges as a future agenda for ODAM research. Most importantly, we see a need for a formal problem definition of ODAM operational planning processes, standard open datasets for comparing multiple performance dimensions, and a universal, multimodal transportation demand model.
\end{abstract}

\section{Introduction}

The rise of megacities/agglomerations together with a tremendous increase in travel demands leads to regular transportation gridlocks in many urban areas all over the world, e.g., in New York, Beijing, Sao Paolo, and Mumbai $[1,2]$. Footage of congestions in these regions is well known; operators and governments try to find solutions towards a better transportation future. The cost of congestion alone in the US is quantified with 305 billion USD for the year 2016 . Increasing the capacities further is not considered a viable option in many cities any longer [3].

The vision of opening the third dimension, i.e., altitude, for urban/regional transportation has gained substantial interest in the last 5-10 years, with significant efforts to explore the so-called on-demand air mobility (ODAM) [4]. The key idea behind ODAM is to use eVTOL (electric vertical takeoff and landing) vehicles for inter- and intracity commutes. These small vehicles (usually anticipated to fly 1-4 people) are envisioned to provide line-by-sight flights at affordable prices, while providing a safe and enjoyable flight experience. Their ability to perform vertical takeoff/landing enables them to be operated on small-size port infrastructure. A successful implementation of ODAM requires not only the development of new technologies, including vehicle design and advances in engine/propulsion technology, but also considerations of novel operational patterns, concerning its on-demand characteristic. ODAM has the potential to radically change our view of urban/regional mobility and saves time in people's daily commutes as well as on regional thin-haul connections $[5,6]$.

Industry and academia spend a large amount of resources on the development of ODAM. Uber, for instance, is pioneering to push mass adoption of VTOL services for 
urban air transportation. See [7] for a detailed analysis on VTOL market feasibility across four dimensions: vehicle, infrastructure and operations, rider experience, and economics. Uber plans to launch the air taxi service in 2023, starting in Dallas, Texas, and Los Angeles, California [8]. Lilium, a German startup company [9], has completed a test flight in 2017 and plans to provide a public air taxi service for city transportation in 2025. Kitty Hawk, a flying-car startup company [10], also expects to bring air taxi services to passengers in 2023. Partnerships with the two major aircraft manufacturer giants, Boeing and Airbus, further accelerate the progress towards urban air mobility. Airbus is also developing its own air taxi City Airbus [11], which is embedded in the EU-initiative Urban Air Mobility. Boeing recently acquired an aviation taxi developer, Aurora Flight Sciences, which is developing a passenger VTOL vehicle. RWTH Aachen University develops a regional air taxi [12] in cooperation with the University of Applied Sciences, Aachen, and the expected entry to service of the Silent Air Taxi is 2024. Future pandemics, such as COVID-19, could become particular drivers of on-demand (personal) air mobility in the near future $[13,14]$. While many companies are racing to build flying prototypes, the scientific literature on ODAM becomes fuzzy. There is a rich body of research focusing on the technical feasibility of ODAM, such as vehicle design or propulsion system, with several recent reviews on ODAM vehicle design [15], current technology for electronic VTOL drones [16], distributed electronic propulsion technology [17], and design of next-generation urban air mobility vehicles. Research on the operational aspects of ODAM, however, is tremendously scattered, with many studies published in different venues, using different nomenclature, and investigating highly similar, yet distinct research problems.

In order to fill in the gap in the operational ODAM (Note that our study subsumes urban air mobility (UAM), by distinguishing urban ODAM from regional ODAM.) literature, this study makes a twofold contribution. First, we provide a comprehensive literature review on the operational aspects of ODAM. We intentionally leave out both topics vehicle design and propulsion technology as there are excellent surveys on these two topics, see above. Our review covers five main categories: demand estimation methodology, infrastructure/port design/location problem, operational planning problem, operational constraints' identification, and competitiveness with other transportation modes. The second part of this study complements the report of aggregated findings by proposing a list of challenges as a future agenda for ODAM research. One major challenge is to ensure reproducibility of previous ODAM studies. We argue that there is an urgent need for defining and agreeing upon concise research questions for ODAM research, accompanied by benchmark/reference datasets and methodology. The wide range of distinct results on various regions in the world makes it necessary to develop a universal, multimodal ODAM framework, including competition and cooperation with other modalities. Furthermore, we see a lot of potential for studies including uncertainties into ODAM and regarding shared, profitable operations.

The remainder of this paper is organized as follows. Section 2 provides an overview of the state-of-the-art operational aspects of ODAM, followed by an analysis section. Section 3 discusses future research directions exclusively, and Section 4 concludes the study.

\section{State-of-the-Art Operational Aspects of ODAM}

This section provides an overview of the operational aspects of ODAM as reported in the literature. The overall goal is to summarize/compare commonalities and differences among previous studies. Research on the operational aspects of ODAM, however, has appeared in many different venues, using different nomenclature and investigating highly similar, yet distinct research problems. This section aims to derive a consistent classification and unified terminology. Accordingly, we build a classification which is inspired by traditional transportation systems wherever appropriate. We categorize the main results of research studies according to five major categories: demand estimation methodology (Section 2.1), infrastructure/port design/location problem (Section 2.2), operational planning problem (Section 2.3), operational constraints' identification (Section 2.4), and competitiveness with other transportation modes (Section 2.5). Section 2.6 summarizes the major conclusions obtained in this section and lays the foundations to identify opportunities for the operational aspects of ODAM in Section 3.

2.1. ODAM Demand Estimation Methodology. As a new emerging transportation mode, demand is the fundamental driver for the development of ODAM, and it is critical for the market orientation for ODAM operators at a strategic level. Table 1 provides an overview of the ODAM demand estimation, including the region under study, time frame, urban or regional scope, data usage and their availability, and a short summary. The studies are sorted by operational scales (urban, regional, and urban + regional) and then by region.

Regarding urban ODAM, we review the work for the region in Europe and U. S. separately. Fu et al. [18] conducted a stated preference survey with 248 respondents from Munich, Germany, investigating the mode choice behavior among four transportation alternatives: public transportation, private car, autonomous taxi, and autonomous air taxi. Results show that travel time, travel cost, and safety are the critical determinants for the adoption of autonomous transportation modes. Moreover, higher value of time and higher income also favor the use of urban air mobility. For a typical European city, Decker et al. [19] used a substitution rate of $10 \%$ of car traffic by a personal air vehicle, assuming 
TABle 1: An overview of the ODAM demand estimation.

\begin{tabular}{|c|c|c|c|c|c|c|}
\hline Ref. & Region & Time frame & Scale & Data type & $\begin{array}{l}\text { Data } \\
\text { avail. }\end{array}$ & Short summary \\
\hline [18] & $\begin{array}{l}\text { Munich, Germany (248 } \\
\text { respondents) }\end{array}$ & $\begin{array}{l}\text { Feb.-Apr. } \\
2018 \text { (survey } \\
\text { time) }\end{array}$ & $\mathrm{U}$ & Stated preference survey & No & $\begin{array}{l}\text { Travel time, travel cost, and safety are } \\
\text { the most critical determinants for the } \\
\text { adoption of autonomous } \\
\text { transportation modes. Moreover, } \\
\text { higher value of time and higher income } \\
\text { also favor the use of urban air mobility. }\end{array}$ \\
\hline [19] & European cities & Future & $\mathrm{U}$ & Scenario assumption & No & $\begin{array}{l}\text { For a typical European city, a } \\
\text { substitution rate of } 10 \% \text { of car traffic by } \\
\text { a personal air vehicle is used, assuming } \\
\text { that daily car traffic is approximately } \\
300,000 \text {. Several requirements are not } \\
\text { easy to be met, and a broad range of } \\
\text { uncertainty remains. }\end{array}$ \\
\hline [20] & New York, U. S. & Future & $\mathrm{U}$ & New York City taxi records & No & $\begin{array}{l}\text { Certain locations including large } \\
\text { facilities and smaller stops for New } \\
\text { York City are suggested. The } \\
\text { percentage of time savings and } \\
\text { willingness to fly did not impact the } \\
\text { location decision significantly, while } \\
\text { the on-road travel limit does. }\end{array}$ \\
\hline [21] & $\begin{array}{c}\text { Northern California and } \\
\text { Washington-Baltimore } \\
\text { Region, U. S. }\end{array}$ & Future & $\mathrm{U}$ & $\begin{array}{l}\text { National household travel } \\
\text { survey, LODES, ACS, and } \\
\text { StreetLight data }\end{array}$ & No & $\begin{array}{l}\text { The demand is very sensitive to the } \\
\text { pricing structure, and the costs have to } \\
\text { be kept between } \$ 1 \text { per passenger mile } \\
\text { and } \$ 1.25 \text { per passenger mile to achieve } \\
\text { a potential market share of } 0.5-4 \% \text {, } \\
\text { where a } 4 \% \text { market share represents } \\
320,000 \text { trips per day. }\end{array}$ \\
\hline
\end{tabular}

cities: Atlanta Boston,

[22]

Dallas, San Francisco, and (survey time)

Los Angeles

[23] U. S. (four focus groups)

May 2017

(survey time)

$\mathrm{U}$

Stated preference survey

U. S. (1405 workers in 5 cities: Atlanta, Boston,

[24]

Dallas, San Francisco, and Los Angeles

Germany

[26]

U. S. (3091 counties)

A hypothetical network

[27] with 5 nodes and 1-10 daily trip demands
2030

$1995-2030$

$\mathrm{R}$

$\mathrm{DB} 1 \mathrm{~B}$ and $\mathrm{OAG}$

Mar.-May

2019 (survey time)

$\mathrm{U}$

Stated preference survey

50 OD pairs' samples in Germany

Future

$\mathrm{R}$

Cirrus SR22 aircraft
No results from the survey were provided.

Only survey for one focus group (6 participants) was conducted with some descriptive feedbacks. Results from two No online platforms (Amazon Mechanical Turk and Qualtrics) were compared, and Qualtrics is recommended to use in the future.

The survey settings are very similar to No [22]. No results from the survey were provided.

With the ODAM door-to-door travel speeds of $80-200 \mathrm{~km} / \mathrm{h}$, a willingness-

No to-pay value of $0.5-0.8 € / \mathrm{km}$ (monetary value in 2015) for the year 2030 is derived for the German market.

More than 600 million on-demand small aircraft trips would compete with automobiles in cost per passenger mile; Partial such number of operations would have negative impacts on the national airspace system, such as airport congestion.

In order to maximize profit, expected $57.7 \%$ of the daily demand should be served/accepted, and an average acceptance rate of approx. 90\% might still allow for profitable operations. 
TABLE 1: Continued.

\begin{tabular}{|c|c|c|c|c|c|c|}
\hline Ref. & Region & Time frame & Scale & Data type & $\begin{array}{l}\text { Data } \\
\text { avail. }\end{array}$ & Short summary \\
\hline [28] & Germany & Future & $\mathrm{U}+\mathrm{R}$ & $\begin{array}{l}\text { Jeppesen airport database } \\
\text { and census } 2011 \text { data } \\
\text { provided by German } \\
\text { Federal Statistical Office }\end{array}$ & No & $\begin{array}{l}\text { A market share of } 19 \% \text { or } 235 \text { million } \\
\text { trips are estimated for Germany, } \\
\text { assuming passenger-specific costs of } \\
0.4 € / \mathrm{km} \text { for ODAM services, } 0.3 € / \mathrm{km} \\
\text { for cars, and } 0.32 € / \mathrm{km} \text { for the } \\
\text { contemporary commercial CS- } 25 \\
\text { aircraft. }\end{array}$ \\
\hline [29] & Zurich, Switzerland & Future & $\mathrm{U}+\mathrm{R}$ & Simulation data & No & $\begin{array}{l}\text { Vehicle parameters (cruising speed, } \\
\text { liftoff time, access time, and price) have } \\
\text { a substantial impact on demand and } \\
\text { turnover. }\end{array}$ \\
\hline$[30]$ & U.S. & 2030 & $\mathrm{U}+\mathrm{R}$ & $\begin{array}{l}\text { OAG, American travel } \\
\text { survey, DB1B, FAA airport } \\
\text { database, and BADA }\end{array}$ & No & $\begin{array}{l}\text { The annual county-to-county person } \\
\text { round trips for very light jets, } \\
\text { commercial airline, and automobile at } \\
\text { one-year interval from } 1995 \text { to } 2030 \\
\text { were predicted. }\end{array}$ \\
\hline$[31]$ & Worldwide (4435 cities) & 2042 & $\mathrm{U}+\mathrm{R}$ & Forecast based on ADI 2012 & No & $\begin{array}{l}26 \text { potential markets were identified, } \\
\text { regarding large population, limited } \\
\text { urban mobility, economic city, and } \\
\text { high passenger demand. }\end{array}$ \\
\hline
\end{tabular}

$\mathrm{U}=$ urban; $\mathrm{R}=$ regional.

that daily car traffic is approximately 300,000 . The total range for this reference VTOL vehicle is $100 \mathrm{~km}$, with maximum two seats and cruise speed $150-200 \mathrm{~km} / \mathrm{h}$. It was reported that several requirements are not easy to be met, and a broad range of uncertainty remains. With New York City in the U. S. as a case study, Rajendran and Zack [20] estimated the potential air taxi demand based on a subset of the current regular taxi demand, i.e., approximately 300 million individual yellow and green taxi ride records from January 2014 to December 2015. An air taxi service is eligible only if the travel time of the air taxi is at least $40 \%$ shorter than that of the regular taxi, with the assumption that the maximum air taxi travel distance is 120 miles $(193 \mathrm{~km})$ and with cruise speed $170 \mathrm{mph}(273 \mathrm{~km} / \mathrm{h})$. With Northern California and Washington-Baltimore region as case studies, Syed et al. [21] proposed an integrated approach to estimate the ODAM demand using the C-logit model, taking into account socioeconomic information, life cycle cost, fare structures, route constraints, and landing site requirements. Preliminary results show that the demand is very sensitive to the pricing structure, and it is estimated that the ODAM costs have to be kept between $\$ 1$ per passenger mile and $\$ 1.25$ per passenger mile to achieve a potential market share of $0.5-4 \%$, where a $4 \%$ market share represents 320,000 trips per day. A 4-passenger-seat aircraft is subject to the assumption that an average of 2.4 passengers per aircraft would generate 133,000 flights per day, even without taking reposition flights into consideration. Note that weather conditions, public acceptance of a fully autonomous flying vehicle, and its certification costs were not considered in this study. In summary, existing work often assumes ODAM demand comes from traditional ground transportation, and among several uncertainty factors, travel time and travel cost are the most critical for the profitability of ODAM operations.

Furthermore, stated preference surveys were designed to ask potential travelers in the U. S. which transportation modes they would take under hypothetical situations. Binder et al. [22] presented details of a survey for estimating commuters' willingness to pay for eVTOL flights in urban areas in the U. S., collecting responses from approximately 2,500 high-income workers with an average one-way commuting time of 45 minutes or more by the individual. Three typical modes (transit, car, and ride-share) are compared with eVTOLs, where travel cost by typical ground transportation modes ranges from $\$ 2.5$ to $\$ 20$, and the travel cost by eVTOLs ranges from $\$ 5$ to $\$ 45$, depending on the travel distance. Maximum travel time is two hours for noneVTOL modes. Access/egress/waiting times, transfer, and ride guarantee availability of different modes are included. Personality, lifestyle characteristics, sociodemographics, and socioeconomic information of the respondents are included as well. Garrow et al. [23] used an online survey to identify ODAM demand segments and quantify willingness to pay for different ODAM alternatives; two online platforms, Amazon Mechanical Turk and Qualtrics, were used to conduct the surveys. Prior trip characteristics, traveler itinerary characteristics, and sociodemographics were also considered. They also conducted a second survey with approximately 100 questions [24], and the survey settings were very similar to [22]. Four commuting modes, transit, traditional car, self-driving car, and piloted air taxi, are 
compared. No results from the survey were provided. Note that all travel costs for these four modes in the survey were assumed as $\$ 5$. We can observe that findings from stated preference surveys are rather constrained, and the implications for ODAM operations are limited.

Regarding regional ODAM, Kreimeier et al. [25] performed an economical assessment of ODAM for the German market for the year 2030, with a door-to-door travel speed of $80-200 \mathrm{~km} / \mathrm{h}$, and a willingness-to-pay value of $0.5-0.8 € / \mathrm{km}$ (monetary value in 2015) is derived. Smith et al. [26] analyzed the potential impacts of autonomous, electric ondemand small aircrafts on the national airspace system for 3,091 counties in the U.S. based on the projected demand for the year 2030 by Baik et al. [30]. It was found that a large number of on-demand small aircraft trips would compete with automobiles in cost per passenger mile; such number of operations would have tremendous negative impacts on the national airspace system, especially congestion around airports. Using a hypothetical network example with five nodes and 1-10 daily trip demands, Mane and Crossley [27] evaluated the impact of accepting different percentages of passenger-demanded trips and fleet size on the potential profitability of ODAM services. It was shown that, in order to maximize profit, expected $57.7 \%$ of the daily demand should be served/accepted; and an average acceptance rate of approximately $90 \%$ might still allow for profitable operations.

Regarding urban and regional ODAM, Kreimeier et al. [28] estimated the potential market size of thin-haul ODAM services in Germany, with a comprehensive analysis of the entire German population and their linear spatial distances to feasible airfields. It was shown that a market share of $19 \%$ or 235 million trips are estimated for Germany, assuming passenger-specific costs of $0.4 € / \mathrm{km}$ for ODAM services, $0.3 € / \mathrm{km}$ for cars, and $0.32 € / \mathrm{km}$ for the contemporary commercial CS-25 aircraft. Balac et al. [29] presented a methodology for demand estimation of personal aerial vehicles in urban settings, with the area of $30 \mathrm{~km}$ radius around the city center of Zurich, Switzerland, as a case study. The minimum number of vehicles needed to serve all trips was formulated as a minimum cost network flow problem and solved by a Gurobi Optimizer. It was shown that the vehicle parameters (cruising speed, liftoff time, access time, and price) have a substantial impact on the ODAM demand and turnover. However, in order to reduce computational burden, only $10 \%$ of the population in the area of $30 \mathrm{~km}$ radius circle around the Zurich city center was sampled. It was assumed that vehicles travel in a straight line, without considering the constraints of infrastructure (landing platforms or parking locations); the capacity of each vehicle was set to be one passenger. Baik et al. [30] presented a modelling framework to predict the annual county-to-county person round trips for the air taxi, commercial airline, and automobile at one-year intervals from 1995 to 2030. Based on a traditional gravity model to estimate ODAM demand and forecasting the air passenger demand between 4,435 settlements worldwide for the year 2042, Becker et al. [31] identified 26 interurban potential markets. However, the maximum range of ODAM was limited to $300 \mathrm{~km}$.
In summary, we can observe that most studies focus on the U. S., while a few focus on Germany and Switzerland, as well as one for the worldwide market. There is no common agreement on which market (urban or regional or both) is more profitable for the ODAM operators. Often, there are fundamentally different parameter settings and different assumptions on flight missions depending heavily on the case study under consideration. Significant uncertainties and discrepancies in the demand estimation have been identified, and these study results cannot be compared in a consistent way. There is no significant amount of data available from the previous studies in order to compare and understand the results and their implications better.

\subsection{ODAM Infrastructure/Port Design and Location Problem.} In the last few years, several terminologies for ODAM infrastructures have been proposed, such as vertiport, skyport, skypark, and airpark. In the following, we do refer to original terminologies, whenever applicable. Table 2 provides an overview of the ODAM infrastructure/port design and location problem, including the region under study, vehicle type, size of the problem, data usage, data availability, and a short summary. The studies are sorted by vehicle types (STOL, VTOL, and eVTOL) and then by region. We discuss each of these studies in detail in the following.

Potential locations of airparks for the vehicle type STOL in two U. S. cities, Miami and South Florida, have been recently studied. Based on the FAA Obstacle Data Team's database, Robinson et al. [32] estimated the geodensity of airparks suitable for short takeoff and landing ODAM operations. Four individual airpark construction types were analyzed: vacant land construction, barge construction, additive construction, and pre-existing airport incorporation. Preliminary results for the Miami metropolitan area show that an average airpark geodensity of 1.66 airparks per square mile can be achieved with a 300 -foot long runway. Somers et al. [33] investigated the impact of the performance of the short takeoff and landing vehicle (ground roll and climb/descent gradient) on the airpark geodensity in the South Florida region, taking into account the constraints of obstacles and weather conditions. The Light Detection and Ranging (LIDAR) data were used to detect the obstacles surrounding vacant parcels, and weather data (wind speeds and wind directions) were taken from the National Oceanic and Atmospheric Administration. It was shown that, in South Florida, doublet runways are needed which make it complex to find suitable parcels due to poor weather conditions, and the climb/descent gradient has to be greater than six degrees.

For the vehicle type VTOL, capacity envelopes of potential vertiports in the U. S. have been analyzed as well. With New York City, U. S., as the case study, Rajendran and Zack [20] proposed an iterative constrained clustering algorithm with the multimodal transportation warm-start technique to identify potential locations for ODAM. The number of locations varies from 10 to 85 . Certain locations including large facilities and smaller stops for New York City are suggested. Surprisingly, they found that the percentage of 
TABLE 2: An overview of the ODAM port design and location problem.

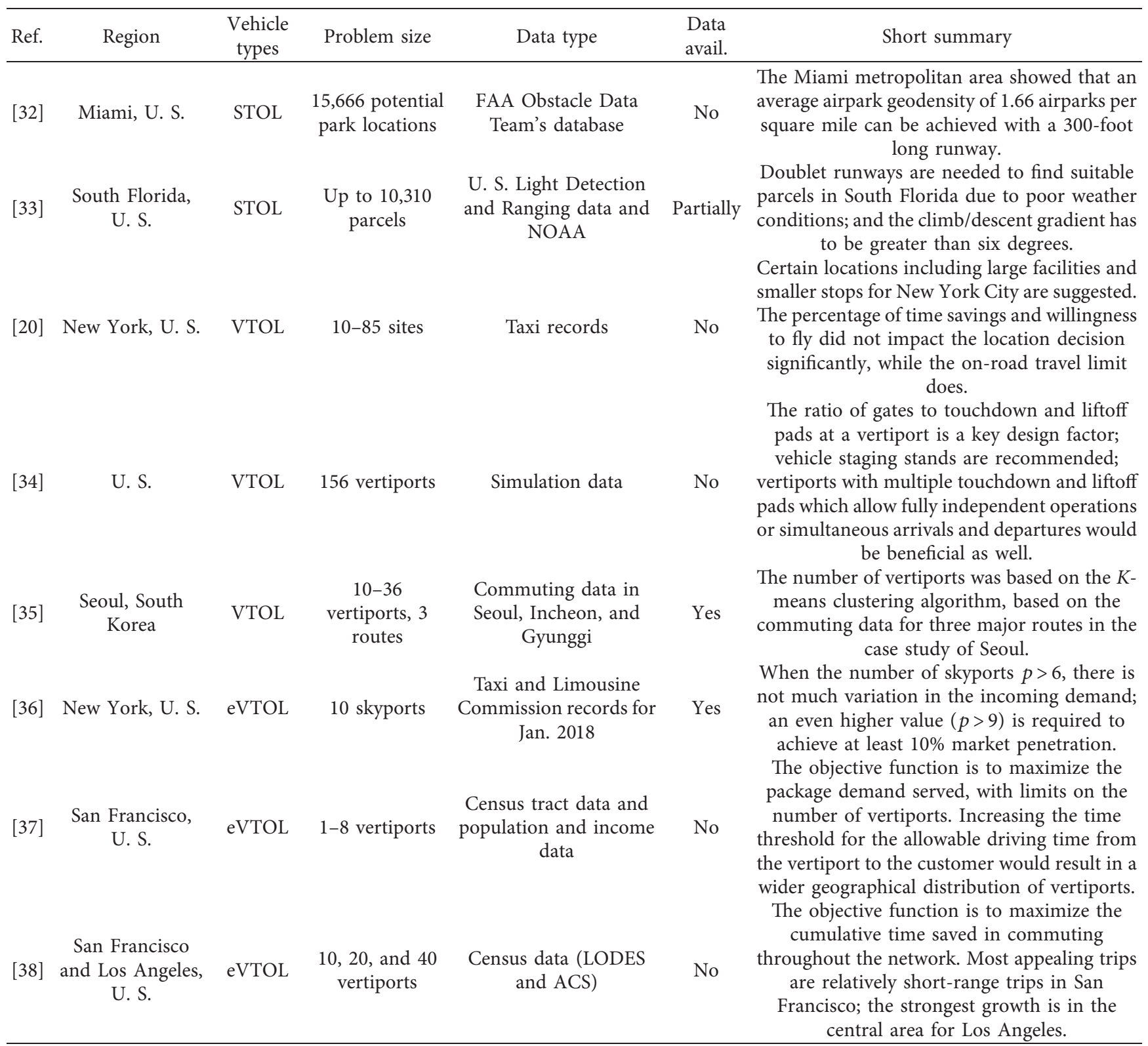

$\mathrm{STOL}=$ short takeoff and landing, $\mathrm{VTOL}=$ vertical takeoff and landing, and $\mathrm{eVOTL}=$ electric vertical takeoff and landing.

time savings and willingness to fly did not impact the location decision significantly, whereas the on-road travel limit (the maximum time for passengers spent on the road) does. Vascik and Hansman [34] used an integer programming approach to derive vertiport capacity envelopes and assess the sensitivity of ODAM vehicle throughput to vertiport topology variations and operational parameters. Four classes of topologies were included: linear topology, satellite topology, pier topology, and remote apron topology. This approach was applied to 156 different vertiports and 146 different operational parameter settings. Results show that the ratio of gates to touchdown and liftoff pads at a vertiport is a key design factor. Moreover, the construction of vehicle staging stands is recommended. Finally, vertiports with multiple touchdown and liftoff pads which allow fully independent operations or simultaneous arrivals and departures would be beneficial as well. Based on Seoul Metropolitan Areas as the case study, Lim and Hwang [35] selected the number of vertiports for three major routes based on the $K$-means clustering algorithm over the commuting data for the cases of 10-36 vertiports. Note that no optimization strategy was used in the selection process of the vertiport location.

For the vehicle type eVTOL, the determination of optimal locations of vertiports in a given region can be modeled as a variant of standard hub location problems (HLPs): how to collect, transfer, and distribute travel demands between origin nodes and destination nodes in a network, see recent reviews on network design in [39-42]. Rath and Chow [36] formulated the air taxi skyport location problem as an 
uncapacitated single allocation $p$-hub median problem (the number of hubs is $p$ ). The objective function is to minimize the travel time for each OD pair in the skyport network, with the consideration of air taxi transfer time and congestion factor on the ground. Gurobi was used to solve this problem with up to 10 skyports for travel demands among 144 taxi zones and 3 airports. Experimental results for New York City show that when the number of skyports $p>6$, there is not much variation in the incoming demand; an even higher value $(p>9)$ is required to achieve at least $10 \%$ market penetration. With San Francisco Bay area as the case study, German et al. [37] examined the use of eVTOL vehicles for small package delivery. The optimal location of the cargo vertiports was formulated as an optimization problem: maximizing the package demand served, with limits on the number of vertiports. However, only 1-8 vertiports were solved for this optimization. Results show that increasing the time threshold for the allowable driving time from the vertiport to the customer would result in a wider geographical distribution of vertiports. The vertiport location problem was further extended by Daskilewicz et al. [38], taking into account household population density as well as work locations. With San Francisco and Los Angeles as two case studies, the new objective function is to maximize the cumulative time saved in the network, with three different network sizes: 10,20 , and 40 vertiports. It was found that most appealing trips are relatively short-range trips in San Francisco; the strongest growth in eVTOL use is in the central area for Los Angeles. Moreover, Wawrzyniak et al. [43] analyzed the ODAM network based on complex network theory using real-world cargo aircraft movement data within the U. S. Central Command area of responsibility in the year 2006.

In summary, similar with the case of demand estimation, most previous studies cover the U. S., except one study for Seoul, South Korea [35]. Therefore, the universal applicability of these results to other regions in the world is very limited since different metropolitan areas have distinct socio-economic-demographic characteristics. The vehicle type covers STOL, VTOL, and EVTOL, among which the majority of studies in the literature focuses on VTOL. The problem size for the ODAM infrastructure design and location problem is rather limited in the literature because of the computational complexity. There are some studies which compute optimal solutions for very small size of the problem, for instance, less than 10 skyports/vertiports $[36,37]$, while a few studies consider more than 10,000 potential locations [32,33] using heuristics and rules of thumb to obtain the solutions. Tradeoffs between the level of accuracy and the computational complexity need to be further explored. Moreover, there is no well-defined reference benchmark dataset as well as solution techniques for the ODAM infrastructure location problem; therefore, it is difficult to reproduce the results and perform comparative analysis and further extensions.

2.3. ODAM Operational Planning Problem. This section summarizes the literature on operational planning of ODAM. Table 3 provides an overview of the ODAM operational planning problem, including the region under study, vehicle type, size of the problem, mathematical formulation, solution technique, and a short summary. The studies are sorted by vehicle types (general vehicles, small jet, very light jet, and eVTOL) and then by region.

Traditionally, there are three horizons in the airline planning process for scheduled air transportation: long-term strategic planning, midterm tactical planning, and operational planning [54]. Strategic planning involves customer demand forecasting, market segmentation, and branding and marketing strategies; tactical planning addresses flight scheduling (which determines the optimal daily schedule of flight operations) and fleet assignment (where an aircraft type is assigned to each flight in the schedule); operational planning deals with aircraft scheduling (which decides a sequence of flight legs to an individual aircraft, and it is often decomposed into aircraft routing and tail assignment) and crew scheduling (the pairing of crew resources according to the flight schedules). The traditional aircraft scheduling problem has always been the main focus of the airline industry since fuel consumption, crew salaries, and aircraftrelated cost typically represent the largest expense for an airline. For large commercial airlines, this problem is usually combined with flight scheduling $[55,56]$, fleet assignment [57], and crew scheduling [58]. A wide range of research has been proposed to tackle this problem such as the classic flight string model [59].

The business model of ODAM shares large similarities with existing on-demand aviation services, especially fractional management companies. Among on-demand aviation services, there are several types of programs: fraction ownership, timeshare, and joint ownership [60]. While fraction ownership allows different stakeholders to use aircraft resources for a fraction of time at different levels, much research has been done for the scheduling of the fractional operation business model [61-64]. See [65] for an excellent review on the vehicle routing problem with pickup and delivery, with four areas of applications, the dial-a-ride problem, the urban courier service problem, the dial-a-flight problem, and the emergency vehicle dispatch problem, focusing on the problem formulation and solution algorithms.

Few studies investigate the operation planning problem for general vehicles. Van der Zwan et al. [44] adopted the set partition model [61] and provided a detailed description of the aircraft routing problem for per-aircraft air taxi operator. Contrary to the column generation solution methodology applied in [61], they used a $k$-shortest path algorithm to generate feasible routing pools for the set partition. With a number of 19-25 air taxis for 225 airports over the 72-hour time horizon, CPLEX was applied to solve the set-partitioning model. However, only virtual test environment and virtual air taxi operator data were used due to the lack of real air taxi operational data. Kohlman and Patterson [45] presented an urban air mobility network model for rapid simulation, consisting of four parts: network definition and mission model, vertiport model, vehicle model, and demand model. The concurrent on-demand vehicle design and vehicle location problem has been investigated as well. In order to solve concurrent aircraft design and operation planning problems, 
TABLE 3: An overview of the ODAM operational planning problem.

\begin{tabular}{|c|c|c|c|c|c|c|}
\hline Ref. & Region & $\begin{array}{l}\text { Vehicle } \\
\text { type }\end{array}$ & Problem size & $\begin{array}{l}\text { Mathematical } \\
\text { formulation }\end{array}$ & Solution technique & Short summary \\
\hline$[44]$ & $\begin{array}{l}\text { Fly Aeolus, } \\
\text { Belgium }\end{array}$ & General & $\begin{array}{l}225 \text { airports, } 19-25 \\
\text { vehicles, } 7-15 \text { flight } \\
\text { daily requests, and } 15 \\
\text { closest trips for a route }\end{array}$ & $\begin{array}{l}\text { Set-partitioning } \\
\text { model }\end{array}$ & $\begin{array}{l}\text { Exact solution with } \\
\text { CPLEX }\end{array}$ & $\begin{array}{l}\text { The developed aircraft routing } \\
\text { system consisted of model creator, } \\
\text { CPLEX, and the solution module. } \\
\text { The number of closest trips that are } \\
\text { appended to a trip to a route is } 3-15 \text {, } \\
\text { and this parameter has a large effect } \\
\text { on the feasible routes and the } \\
\text { computational time. }\end{array}$ \\
\hline$[45]$ & Hypothetical & General & N/A & N/A & N/A & $\begin{array}{l}\text { An urban air mobility network } \\
\text { model for rapid simulation was } \\
\text { presented, consisting of four parts: } \\
\text { network definition and mission } \\
\text { model, vertiport model, vehicle } \\
\text { model, and demand model. }\end{array}$ \\
\hline [46] & Hypothetical & General & 10 airports & Integer program & $\begin{array}{l}\text { Exact solution with } \\
\text { CPLEX }\end{array}$ & $\begin{array}{l}\text { Concurrent aircraft design and } \\
\text { operation planning problems were } \\
\text { combined together; its integer } \\
\text { programming model entailed } \\
\text { revenue-generating trips, non- } \\
\text { revenue-generating trips, and } \\
\text { charter flights. }\end{array}$ \\
\hline [47] & $\begin{array}{l}\text { FlySmart, } \\
\text { Norway }\end{array}$ & Small jet & $\begin{array}{l}12 \text { airports, } 10 \text { vehicles, } \\
\text { and } 200 \text { daily bookings }\end{array}$ & $\begin{array}{c}\text { Dial-a-flight } \\
\text { problem model }\end{array}$ & $\begin{array}{c}\text { Heuristics } \\
\text { (insertion }+ \text { local } \\
\text { search) }\end{array}$ & $\begin{array}{l}\text { The required air taxi fleet to handle } \\
\text { approximately } 100 \text { booking } \\
\text { requests is close to } 15 \text {, and } \\
\text { confirming the pickup times } \\
\text { immediately to the customers can } \\
\text { provide as good solutions as } \\
\text { postponing the confirmation the } \\
\text { night before. }\end{array}$ \\
\hline [48] & $\begin{array}{l}\text { Etirc Aviation, } \\
\text { Europe }\end{array}$ & $\begin{array}{c}\text { Very } \\
\text { light jet }\end{array}$ & $\begin{array}{l}10 \text { airports, } 38 \text { routes, } \\
\text { and } 270 \text { weekly flights }\end{array}$ & $\begin{array}{c}\text { Dial-a-ride } \\
\text { problem model }\end{array}$ & $\begin{array}{c}\text { Dynamic } \\
\text { programming }\end{array}$ & $\begin{array}{l}\text { An average of } 5.5 \% \text { cost advantage } \\
\text { is achieved on the cost of empty } \\
\text { legs; the addition of a two-hour time } \\
\text { window in operations increases the } \\
\text { customer acceptance rate with } \\
2-3 \% \text {. }\end{array}$ \\
\hline [49] & $\begin{array}{c}\text { North } \\
\text { Carolina, U. S. }\end{array}$ & $\begin{array}{c}\text { Very } \\
\text { light jet }\end{array}$ & $\begin{array}{l}5 \text { airports, } 10 \text { routes, } \\
\text { and } 50-250 \text { weekly } \\
\text { passengers per route }\end{array}$ & $\begin{array}{l}\text { Discrete-event } \\
\text { model and flow } \\
\text { model }\end{array}$ & Gradient algorithm & $\begin{array}{l}\text { An application of these two models } \\
\text { on air taxi pricing showed that the } \\
\text { flow model could be used for a } \\
\text { pricing application. }\end{array}$ \\
\hline [50] & U. S. & $\begin{array}{l}\text { Very } \\
\text { light jet }\end{array}$ & $\begin{array}{l}\text { 12-75 vehicles (test } \\
\text { scenario) }\end{array}$ & N/A & N/A & $\begin{array}{l}\text { A fast-time simulation tool was } \\
\text { developed to understand the } \\
\text { complex dynamics of air taxi } \\
\text { networks. }\end{array}$ \\
\hline [51] & Hypothetical & eVTOL & $\begin{array}{l}3 \text { vertiports, } 20 \text { vehicles, } \\
\text { and } 6 \text { routes }\end{array}$ & $\begin{array}{l}\text { Mixed-integer } \\
\text { quadratic } \\
\text { program }\end{array}$ & $\begin{array}{l}\text { Gurobi solver (plan } \\
\text { to use) }\end{array}$ & $\begin{array}{l}\text { Three variants of basic formulation } \\
\text { models for different types of } \\
\text { ODAM services were presented. } \\
\text { However, these models were not } \\
\text { being implemented, and no } \\
\text { numerical experiment results were } \\
\text { provided. }\end{array}$ \\
\hline$[52]$ & Hypothetical & eVTOL & N/A & N/A & N/A & $\begin{array}{l}\text { An open-source multiagent } \\
\text { transportation simulation } \\
\text { framework was developed, } \\
\text { considering the effects of variations } \\
\text { in vehicles as well as infrastructure } \\
\text { locations. }\end{array}$ \\
\hline
\end{tabular}


TABle 3: Continued.

\begin{tabular}{cccccc}
\hline Ref. & Region & $\begin{array}{c}\text { Vehicle } \\
\text { type }\end{array}$ & Problem size & $\begin{array}{c}\text { Mathematical } \\
\text { formulation }\end{array}$ & Solution technique \\
\hline [53] Hypothetical & eVTOL & 10-40 vehicles & $\begin{array}{c}\text { Mixed-integer } \\
\text { linear program }\end{array}$ & $\begin{array}{c}\text { A sequencing and scheduling } \\
\text { algorithm for ODAM arrivals was } \\
\text { proposed, and it can be solved } \\
\text { within } 79 \text { seconds for up to } 40 \\
\text { incoming vehicles. }\end{array}$ \\
\hline
\end{tabular}

$\mathrm{eVOTL}=$ electric vertical takeoff and landing.

Mane and Crossley [46] combined aircraft allocation and aircraft design together; its integer programming model entailed revenue-generating trips, non-revenue-generating trips, and charter flights. Due to the model complexity, an instance of 10 city nodes was tested through direct CPLEX implementation.

For the small jet vehicle type, Fagerholt et al. [47] presented a simulation methodology to support strategic decisions for an air taxi company in Norway (FlySmart), including fleet size, price differentiation strategies, and booking confirmation policies. A heuristic with insertion and local search was used to optimally distribute waiting time along a single aircraft schedule. A fleet of ten aircrafts with approximately 200 daily bookings and $1-4$ passengers for each booking were used as case studies.

For the very light jet vehicle type, de Jong [48] modeled the air taxi dispatch problem (which is defined as a timescheduled trip being part of a single aircraft route) as a diala-ride problem based on a case study of ten airports, 38 routes, and 270 flight requests per week, representing the air taxi network of Etirc Aviation (a company which operates personalized business flights in Europe and Russia). One selected case study showed that an average of 5.5\% cost advantage is achieved on the cost of empty legs, and the addition of a two-hour time window in operations increases the customer acceptance rate by $2-3 \%$. Note that the standard dial-a-ride problem assumes a homogeneous fleet with a fixed size. A single-provider air taxi service model was used to characterize the week-to-week flow of passengers and the aircraft [49] for the case of 5 airports, 10 routes, and 50-250 weekly passengers per route [66]. Results show that the flow model could be used for a pricing application. Bonnefoy [50] built a fast-time simulation tool to understand the complex dynamics of air taxi networks, including demand modelling with the gravity model, trip generation based on Monte Carlo simulation, aircraft routing, and pilot assignment, as well as unscheduled maintenance events.

For the eVTOL vehicle type, based on the simulated ODAM market demand, Shihab et al. [51] formulated three basic models of scheduling types, fleet dispatching, and fleet planning, with the goal to maximize profit. Three types of services were compared as well: on-demand service, scheduled service, and a mix of both services. However, these models were not implemented, and no numerical experiment results were provided. Rothfeld et al. [52] presented an open-source multiagent transportation simulation framework, MATSim, with the extension of considering the effects of variations in personal aerial vehicles as well as dedicated infrastructure locations. Kleinbekman et al. [53] proposed a sequencing and scheduling algorithm for ODAM arrivals, and experiment results showed that their algorithm can be solved within 79 seconds for up to 40 incoming vehicles. A novel concept of airborne trajectory management for high ODAM traffic densities in a congested urban area has been proposed as well [67].

In summary, we can observe that there are a few studies conducted from the air taxi operator's point of view, including a Belgian air taxi company Fly Aeolus [44], a Norwegian air taxi company FlySmart [47], and the Luxembourg-based air taxi company Etirc Aviation [48], while most studies used hypothetical network operators. Very light jet and electronic vertical takeoff and landing (eVTOL) vehicles are the chosen types. The size of the operational planning problem is very limited, including the number of vehicles, the number of airports (3 vertiports [51] and 5 airports [49]), and the number of served routes (10 routes [49]). The scale of the problem in existing research is far from the envisioned operational scale of ODAM, with the predicted trip demand in a magnitude of million $[26,28]$. Furthermore, different mathematical models have been formulated with distinctive solution techniques; for very small-scale problems, the exact solution with CPLEX was often used $[44,46,53]$, while heuristics are frequently used to solve medium-size problems [47]. Similar with the case of the ODAM infrastructure/port design and location problem, there are no well-defined reference benchmark datasets as well as solution techniques for the ODAM operational planning problem, and thus, it is extremely difficult to reproduce and understand the results from existing work.

\subsection{ODAM Operational Constraints' Identification.}

Although there is a large body of research focusing on the assessment of the technical feasibility of ODAM, operational constraints during the implementation process of the ODAM network at large scale are the bottleneck for achieving market success. Table 4 provides an overview of identified operational constraints for ODAM, including the region under study, vehicle type, fleet size of ODAM vehicles, operational scale (urban vs. regional), data usage and their availability, and a short summary. The studies are sorted by vehicle types (VTOL, personal air vehicle, and general vehicles) and then by region.

For the VTOL vehicle type, Rothfeld et al. [68] analyzed the operation performance of a potential ODAM implementation with the artificial Sioux Falls Network using a 
TABle 4: An overview of the ODAM operational constraints' identification.

\begin{tabular}{|c|c|c|c|c|c|c|c|}
\hline Ref. & Region & $\begin{array}{l}\text { Vehicle } \\
\text { type }\end{array}$ & Fleet size & Scale & Data type & $\begin{array}{l}\text { Data } \\
\text { avail. }\end{array}$ & Short summary \\
\hline$[68]$ & $\begin{array}{l}\text { Artificial Sioux Falls } \\
\text { Network }\end{array}$ & VTOL & $50-300$ & $\mathrm{U}$ & Simulation data & No & $\begin{array}{l}\text { The adoption of ODAM is strongly influenced } \\
\text { by the potential travel time reduction. } \\
\text { It was found that despite the dramatic }\end{array}$ \\
\hline [69] & U. S. and Europe & $\begin{array}{l}\text { Personal air } \\
\text { vehicle }\end{array}$ & N/A & $\begin{array}{c}\mathrm{U} \\
\text { and } \mathrm{R}\end{array}$ & N/A & N/A & $\begin{array}{l}\text { technology innovation, several challenges still } \\
\text { remain in the ultimate application of personal } \\
\text { air vehicles, especially safety, infrastructure } \\
\text { availability, and public acceptance. }\end{array}$ \\
\hline [70] & Los Angeles & General & N/A & $\mathrm{U}$ & $\begin{array}{c}\text { FAA } 5010 \\
\text { database, etc. }\end{array}$ & No & $\begin{array}{l}\text { Identified several critical operational } \\
\text { constraints for ODAM services: noise and } \\
\text { public acceptance, accessibility of takeoff and } \\
\text { landing areas, interaction with air traffic } \\
\text { control, ground infrastructure, and flight } \\
\text { density; potential mitigation strategies against } \\
\text { the first three key operational constraints were } \\
\text { discussed. }\end{array}$ \\
\hline [71] & $\begin{array}{l}3 \text { cities in the U. S. } \\
\text { (Los Angeles, } \\
\text { Boston, and Dallas) }\end{array}$ & General & N/A & $\mathrm{U}$ & $\begin{array}{l}\text { Census data, } \\
\text { consumer wealth } \\
\text { data, etc. }\end{array}$ & No & $\begin{array}{l}\text { With } 32 \text { reference missions within these three } \\
\text { cities, it was found that the three most } \\
\text { stringent constraints are noise acceptance, } \\
\text { availability of takeoff and landing areas, and } \\
\text { scalability of air traffic control. }\end{array}$ \\
\hline$[72]$ & $\begin{array}{l}\text { Dallas-Fort Worth } \\
\text { area }\end{array}$ & General & $\begin{array}{l}115-225 \\
\text { flights }\end{array}$ & $\mathrm{U}$ & $\begin{array}{l}\text { Field experiment/ } \\
\text { test data }\end{array}$ & No & $\begin{array}{l}\text { It was found that helicopter routes and } \\
\text { communication procedures in the current day } \\
\text { can support near-term urban air mobility } \\
\text { operations, but may not be scalable. }\end{array}$ \\
\hline [73] & General & General & $\mathrm{N} / \mathrm{A}$ & $\mathrm{U}$ & N/A & N/A & $\begin{array}{l}\text { Several relevant factors regarding the } \\
\text { integration of ODAM to the urban city } \\
\text { transportation environment were discussed, } \\
\text { such as ownership structure, adaptability of } \\
\text { schedules, and demand drivers. }\end{array}$ \\
\hline [74] & Munich, Germany & General & N/A & $\mathrm{U}$ & N/A & N/A & $\begin{array}{c}\text { Preliminary results for the case study of } \\
\text { Munich show that rents in all city centers } \\
\text { increase, while the household's average utility } \\
\text { decreases. }\end{array}$ \\
\hline
\end{tabular}

$\mathrm{U}=$ urban; $\mathrm{R}=$ regional.

multiagent simulation tool, MATSim [52]. Varying parameters have been tested: vehicle cruise speed $(50-450 \mathrm{~km} /$ $\mathrm{h})$, vehicle takeoff and landing speed $(5-20 \mathrm{~m} / \mathrm{s})$, groundbased process time $(0.5-20 \mathrm{~min})$, passenger capacity $(1-12)$, fleet size (50-300), and the number of vertiports (4-10). Simulation results show that the adoption of ODAM is strongly influenced by the potential travel time reduction. However, only homogeneous vehicles are simulated, and the price of using ODAM is assumed to be three times the car price.

For personal air vehicles, Liu et al. [69] provided an overview of research activities with the focus on the U.S. and Europe. It was found that, despite dramatic technology innovation, several challenges still remain in the ultimate application of personal air vehicles, especially safety, infrastructure availability, and public acceptance.

Most studies on the identification of the ODAM operational constraints are for general vehicles. With the Los Angeles Basin as the case study, Vascik and Hansman [70] identified several critical operational constraints for ODAM services: noise and public acceptance, accessibility of takeoff and landing sites, interaction with air traffic control, ground infrastructure, and flight density. They also discussed potential mitigation strategies against the first three key operational constraints. The authors further investigated three major cities in the U. S. (Los Angeles, Boston, and Dallas) [71]. With 32 reference missions within these three cities, it was found that the three most stringent constraints are noise acceptance, availability of takeoff and landing sites, and scalability of air traffic control.

The routes and procedures for urban air mobility based on the existing helicopter routes have been investigated as well. With Dallas-Fort Worth area as the case study, Verma et al. [72] investigated routes and procedures for urban air mobility based on the existing helicopter routes along with different communication procedures. Three different levels of traffic were evaluated: low (115 flights), medium (167 flights), and high (225 flights). Field test data showed that helicopter routes and communication procedures on the current day can support near-term urban air mobility operations, but may not be scalable due to extra workload for air traffic controllers.

Moreover, the integration of the urban air mobility with the city transportation has been studied recently. 
Straubinger and Raoul [73] discussed several relevant factors regarding the integration of urban air mobility to the city transportation environment, such as ownership structure (private vs. rental), adaptability of schedules (scheduled vs. on-demand), and demand drivers (job vs. housing). Furthermore, the authors developed an urban spatial computable general equilibrium model to assess the welfare changes for the urban air mobility integration [74]. Preliminary results for the case study of Munich show that rents in all city centers increase, while the household's average utility decreases.

In summary, there seems to be a consensus that the public acceptance, infrastructure availability, and scalability of ODAM operations are critical operational constraints. However, different problem definitions have been considered in the literature, for instance, personal air vehicles indicating the ownership of the vehicle itself [69] and urban air mobility being part of the city transportation system $[73,74]$, inducing different operational concepts and business models. Furthermore, the projects in the field of ODAM research have not been commonly planned or coordinated, which makes the accessibility to the in-depth findings and analysis results difficult.

\subsection{Competitiveness of ODAM with Existing Transportation} Modes. As a new emerging transportation mode, ODAM has the potential to relieve the grid-locked ground transportation in megacities by leveraging the third spatial dimension. Table 5 provides an overview of the competitiveness of ODAM compared with existing transportation modes, including the region under study, operational scale (urban vs. regional), data usage and their availability, competition modes, evaluation criteria, and a short summary. The studies are sorted by scale (urban and urban + regional) and then by region.

Most studies focus on urban ODAM; stated preference surveys were often used to identify the mode choice behavior among different transportation modes. Fu et al. [18] conducted a stated preference survey with 248 respondents in Munich, Germany, regarding the mode choice behavior among four transportation alternatives: public transportation, private car, autonomous taxi, and autonomous air taxi. Five different criteria were applied: total travel time, total travel cost, safety, inconvenience, and multitasking possibility. Results show that the first three are the most critical determinants for the adoption of autonomous transportation modes. Moreover, higher value of time and higher income also favor the use of urban air mobility. Moreover, there are some studies on the U. S. regions. Binder et al. [22] presented details of a survey for estimating commuters' willingness to pay for eVTOL in 5 cities, Atlanta, Boston, Dallas, San Francisco, and Los Angeles in the U. S., collecting responses from 2,500 high-income workers whose average one-way commuting time is 45 minutes or more by the individual. Four transportation modes are compared, transit, traditional personal car, selfdriving car, and piloted air taxi, regarding multiple criteria: travel time, travel cost, access/egress/waiting times, transfer, and ride guarantee availability of different modes. Furthermore, Garrow et al. [24] conducted a second survey among 1,405 respondents in the same five cities in the U. S. as in [22], and the survey settings with approximately 100 questions are very similar to [22], so as the same for transportation mode alternatives and evaluation criteria. However, no results from both surveys mentioned above were provided.

Travel time, specifically door-to-door travel time, is the most critical factor for the competitiveness of different transportation modes. There are two studies regarding the competitiveness of ODAM: one for the U. S. and the other one for Europe. Wei et al. [75] proposed a methodology to analyze the door-to-door commuting time of short takeoff and landing vehicles, compared with personal cars. A total of 4,529 different commutes between 1,035 unique census tracts in South Florida were used as the case study. A sensitivity analysis of the door-to-door travel time against the vehicles' takeoff distance, cruise speed, ground handling time, climb rate, and cruise altitude was performed. It was found that takeoff distance and cruise speed are the two most important parameters for the benefits of ODAM. Reducing the takeoff distance is important in order to be able to find a sufficient number of vertiport locations. For South Florida, ODAM operations should target for ground commutes more than $45 \mathrm{~min}$, and the vehicles should be able to take off from runways of $500 \mathrm{ft}$, with cruising speeds over $160 \mathrm{kts}$. Note that commutes shorter than $30 \mathrm{~min}$ are filtered out because of lack of incentives to switch to an ODAM service.

For the scale of urban and regional ODAM, Sun et al. [76] designed and implemented a door-to-door travel time estimation framework to analyze the potential competitiveness of ODAM when competing with existing transportation modes (car, railway, and aircraft), and 29 countries in Europe were used as case studies. Results show that while the major competitor for ODAM in Europe is railway, the competitiveness of air taxi service, however, largely depends on the region. These 29 European countries have a large potential to benefit from air taxi service up to $450 \mathrm{~km}$ because the periphery of Europe has the largest potential for ODAM services.

Although travel time is appealing for the adoption of ODAM, travel cost is also one decisive factor for the competitiveness of ODAM. Uber estimated that the price for personal air vehicles is at the level of Uber Black or optimistically as low as its cheapest service UberX price [77]. Regarding the potential market size of thin-haul ODAM services in Germany, Kreimeier et al. [28] estimated a market share of $19 \%$ or 235 million ODAM trips, with the assumption that passenger-specific costs will be $0.4 € / \mathrm{km}$ for ODAM services, $0.3 € / \mathrm{km}$ for cars, and $0.32 € / \mathrm{km}$ for contemporary commercial CS-25 aircrafts. With Northern California and Washington-Baltimore region, U. S., as two case studies, Syed et al. [21] estimated that the ODAM costs have to be kept between $\$ 1$ per pax mile and $\$ 1.25$ per pax mile to achieve a potential market share of $0.5-4 \%$, where a $4 \%$ market share represents 320,000 trips per day. ODAM is used for different range classes, and this alone leads to seemingly inconsistent results (e.g., urban air mobility $\$ 2$ per 
TABLE 5: An overview of the competitiveness of ODAM with existing transportation modes.

\begin{tabular}{|c|c|c|c|c|c|c|c|}
\hline Ref. & Region & Scale & Data type & $\begin{array}{l}\text { Data } \\
\text { avail. }\end{array}$ & Competitive modes & Evaluation criteria & Short summary \\
\hline [18] & $\begin{array}{l}\text { Munich, } \\
\text { Germany }\end{array}$ & $\mathrm{U}$ & $\begin{array}{l}\text { Stated preference } \\
\text { survey }\end{array}$ & No & $\begin{array}{l}\text { Public transport, } \\
\text { private car, } \\
\text { autonomous taxi, } \\
\text { and autonomous } \\
\text { air taxi }\end{array}$ & $\begin{array}{l}\text { Total travel time, total } \\
\text { travel cost, } \\
\text { inconvenience, safety, } \\
\text { and multitasking } \\
\text { possibility }\end{array}$ & $\begin{array}{l}\text { Travel time, travel cost, and } \\
\text { safety are the most critical } \\
\text { determinants for the } \\
\text { adoption of autonomous } \\
\text { transportation modes. } \\
\text { Moreover, higher value of } \\
\text { time and higher income } \\
\text { also favor the use of urban } \\
\text { air mobility. }\end{array}$ \\
\hline$[22]$ & $\begin{array}{c}\text { U. S. (2500 } \\
\text { workers in } 5 \\
\text { cities: Atlanta, } \\
\text { Boston, Dallas, } \\
\text { San Francisco, } \\
\text { and Los Angeles) }\end{array}$ & $\mathrm{U}$ & $\begin{array}{l}\text { Stated preference } \\
\text { survey }\end{array}$ & No & $\begin{array}{l}\text { Transit, traditional } \\
\text { personal car, and } \\
\text { ride-share car }\end{array}$ & $\begin{array}{l}\text { Travel time, travel cost, } \\
\text { access/egress/waiting } \\
\text { times, transfer, and ride } \\
\text { guarantee availability of } \\
\text { different modes }\end{array}$ & $\begin{array}{l}\text { No results from the survey } \\
\text { were provided. }\end{array}$ \\
\hline$[24]$ & $\begin{array}{c}\text { U. S. (1405 } \\
\text { workers in } 5 \\
\text { cities: Atlanta, } \\
\text { Boston, Dallas, } \\
\text { San Francisco, } \\
\text { and Los Angeles) }\end{array}$ & $\mathrm{U}$ & $\begin{array}{l}\text { Stated preference } \\
\text { survey }\end{array}$ & No & $\begin{array}{l}\text { Transit, traditional } \\
\text { personal car, and } \\
\text { self-driving car }\end{array}$ & $\begin{array}{l}\text { Travel time, travel cost, } \\
\text { access/egress/waiting } \\
\text { times, transfer, and ride } \\
\text { guarantee availability of } \\
\text { different modes }\end{array}$ & $\begin{array}{l}\text { No results from the survey } \\
\text { were provided. }\end{array}$ \\
\hline$[75]$ & $\begin{array}{l}\text { South Florida, } \\
\text { U. S. }\end{array}$ & $\mathrm{U}$ & $\begin{array}{c}\text { Census } \\
\text { transportation } \\
\text { planning products of } \\
2000 \text { (survey data) }\end{array}$ & No & Personal car & $\begin{array}{l}\text { Door-to-door travel } \\
\text { time }\end{array}$ & $\begin{array}{l}\text { Takeoff distance and cruise } \\
\text { speed are the two most } \\
\text { important parameters for } \\
\text { the benefits of ODAM. For } \\
\text { the South Florida area, } \\
\text { ODAM operations should } \\
\text { target for ground } \\
\text { commutes more than } \\
45 \text { min, and the vehicles } \\
\text { should be able to takeoff } \\
\text { from runways of } 500 \mathrm{ft} \text {, } \\
\text { with cruising speeds over } \\
\text { 160 kts }\end{array}$ \\
\hline$[76]$ & $\begin{array}{l}29 \text { countries in } \\
\text { Europe }\end{array}$ & $\mathrm{U}+\mathrm{R}$ & $\begin{array}{l}\text { OpenStreetMap, } \\
\text { openAIP, and } \\
\text { gridded population } \\
\text { of the world }\end{array}$ & Yes & $\begin{array}{l}\text { Conventional } \\
\text { aircraft, rail, and } \\
\text { personal car }\end{array}$ & $\begin{array}{l}\text { Door-to-door travel } \\
\text { time }\end{array}$ & $\begin{array}{l}\text { The major competitor for } \\
\text { ODAM in Europe is } \\
\text { railway, and the } \\
\text { competitiveness of air taxi } \\
\text { service largely depends on } \\
\text { the region. Furthermore, } \\
\text { these } 29 \text { European } \\
\text { countries have a large } \\
\text { potential to benefit from } \\
\text { air taxi service up to } \\
450 \text { km, and the periphery } \\
\text { of Europe has the largest } \\
\text { potential for ODAM } \\
\text { services. }\end{array}$ \\
\hline
\end{tabular}

$\mathrm{U}=$ urban; $\mathrm{R}=$ regional.

pax $\mathrm{km}$ and regional air mobility less than $\$ 0.65$ per pax $\mathrm{km})$. See [78] for vehicle configurations up to $100 \mathrm{~km}$, as well as the Silent Air Taxi and Lilium for ranges beyond $100 \mathrm{~km}$.

In summary, it is instrumental to compare the competitiveness with existing transportation modes upon the introduction of the ODAM in order to predict the mode choice behavior of travelers more accurately and align the market position for the ODAM service more realistically in the future. From the existing literature, we can observe that in comparison with traditional transportation modes, one major advantage of ODAM is its travel time, both for the case of the U. S. and Europe. However, travel costs estimated 
for ODAM with different range classes (urban vs. regional) seem completely inconsistent; also, market shares were derived incomparably. These inconsistencies make it extremely difficult to judge the profitability of ODAM operations. The unavailability of the large amount of data makes the comparative analysis and assessment even more difficult and less reliable.

2.6. Discussion. We have reviewed recent literature on operational aspects of ODAM, covering five major categories: demand estimation methodology, infrastructure/port design/location problem, operational planning problem, operational constraints' identification, and competitiveness with other transportation modes. Research on the operational aspects of ODAM is widely dispersed and published in different scientific venues, using different nomenclature and investigating highly similar, yet distinct research problems. The major findings of our survey are summarized in the following.

2.6.1. Lack of Formal Problem Definition. While small aircrafts have been used and operated privately for business purposes (general aviation) for decades, the idea of a broad and ubiquitous air taxi network as a mobility service has been promoted, especially since the emergence of new design concepts and propulsion technologies. With this hype, many recent research projects aim at analyzing and optimizing a part of air taxi flight operations, however, without defining a fully established and standardized nomenclature for research projects first. For instance, some studies consider the design and planning of ODAM flight operations from the perspective of typical routing and planning problems and therefore adopt the corresponding vocabulary from standard planning problems of ground traffic (e.g., see [20]). In other studies, on the contrary, assumptions are based on already known general aviation procedures, which is why terms and definitions from this area are used (e.g., see [44]). Furthermore, the aircrafts used for such flight services are sometimes referred to as "air taxis" (e.g., see [27]), but elsewhere also as "personal air vehicles" (e.g., see [5]), suggesting ownership by the passenger himself, and thus a completely different operational concept. This lack of established phraseology, the misuse of language, and, above all, the lack of a real, uniform problem definition often lead to confusion and make it considerably more difficult to understand the current state of air taxi research, let alone to recognize similarities and differences.

2.6.2. Coverage and Inconsistency. Analogous to the nonuniform formulation of the actual research problem, ODAM literature makes different assumptions regarding flight missions, especially depending on the case study (i.e., initial conditions of the area of investigation) and individual project focus. An important distinction is, for example, the intended use and the associated range capacity of the ODAM aircraft. This fundamental difference in initial mission assumptions alone seems to lead to inconsistent study results in terms of operating costs per passenger kilometer, a key measure for comparing study results. In studies with urban applications ("urban air mobility"), flight costs of approx. 2\$/pax/km were calculated; for regional air mobility with a flight distance of up to $500 \mathrm{~km}$, however, less than $0.65 \$ / \mathrm{Pax} /$ $\mathrm{km}$ were calculated (see [28]). In addition, despite many serious efforts of recent ODAM studies to estimate accurate demand in several regions of the world, we have identified a collection of significant uncertainties and discrepancies between the results of these studies. For example, Kreimeier et al. [28] estimated a market share of $19 \%$ or 235 million trips per year for the potential market size of ODAM thinhaul services in Germany, assuming passenger-specific costs of $0.4 € / \mathrm{km}$ for ODAM services, $0.3 € / \mathrm{km}$ for cars, and $0.32 € /$ $\mathrm{km}$ for modern commercial CS-25 aircrafts. In contrast, Decker et al. [19] used a substitution rate of $10 \%$ of car traffic by ODAM for a typical, average European city instead, assuming that daily car traffic is around 300,000 trips. Syed et al. [21] estimated that ODAM costs have to be kept between $\$ 1$ per pax mile and $\$ 1.25$ per pax mile to reach a potential market share of $0.5-4 \%$, with a market share of $4 \%$ representing 320,000 trips per day for Northern California and the Washington-Baltimore region in the U. S. as case studies. As particular projects aim at completely different study areas with heterogeneous characteristics, it is important for the comparison of the study results to have a list of initial study parameters. As mentioned before, individual assumptions of the passenger and range capacity of the study vehicles result in different substitute transport capacities and thus diverging information regarding a possible transport demand. In addition to technical parameters, standardized boundary conditions must also take into account operational factors such as mission time, mission start and end location, possible connections, pricing systems, and accessibility when setting the mission studies.

2.6.3. Applicability of Research Results. As mentioned before, many research projects base their studies on a specific study area (urban or regional areas), adopt its specific characteristics as input values for parameter studies, and align the ODAM network accordingly. However, most previous ODAM research projects focused on large U. S. metropolitan areas (e.g., Los Angeles as in [22] or [70] or San Francisco as in [37]) so that the universal applicability of these results is very limited. Different metropolitan areas all over the world with their demographic, geographical, or topographical characteristics, different demand patterns for air taxi services, and air traffic management systems face different operational challenges. A systematic, comparative analysis of hypothetical ODAM operations in representative regions of the world, which highlights essential differences, is therefore lacking.

2.6.4. Optimality vs. Scalability. Analogous to conventional problems with the design and optimization of networks, ODAM optimization is inherently difficult. With increasing scenario size and additional parameters as the input, the computational complexity and thus the computation time 
also increase significantly so that large computer clusters are required. This often results in a compromise between the level of detail/accuracy and handling/calculation time. Hence, previous studies can generally be assigned to two groups:

(a) Studies that calculate optimal solutions/assignments for very small study areas with a small fleet (3 routes [35]) and only a few requirements, for instance, less than 10 vertiports/skyports/airports [36, 37, 46, 51]. The level of detail and significance is to be regarded as low, but the calculation time is comparatively short.

(b) Studies that consider many heuristics and carry out rules of thumb for large input problems, for example, more than 10,000 potential locations $[32,33]$. This increases the significance; thus, the study results can be classified as comparatively reliable. Handling, on the contrary, is very demanding and requires sufficient computational power and time.

A particular problem here is the fact that there is almost no favorable, useful transition or overlap between the two types of studies as they are often carried out and published at different institutions with different intentions, e.g., in operational research or air traffic management, considering different publication criteria.

\section{Future Research Directions}

As our literature review shows, there are enormous efforts made to understand the potential of ODAM and to use it to revolutionize the way we think about transportation. Nevertheless, based on the above results, we see a whole set of lines for future research on the operational aspects of ODAM. These proposals for research are discussed in the following.

\subsection{Formulation of a Common Lexicon and Adequate ODAM} Research Problems. Due to the comparably young field of research, ODAM research problems are loosely defined, especially in comparison to well-established counterparts in ground traffic and commercial (scheduled) air transportation. This makes it rather challenging to qualitatively capture and evaluate the contributions of specific studies, let alone compare studies and their results on a larger scale. Therefore, we believe that future ODAM projects will benefit significantly from a number of specially aligned ODAM research problems. Established studies can inspire some of these problems, but the focus must be on key differences and peculiarities. In light of the studies reviewed as part of this survey, we propose to use the basic terminology ODAM taxi (covering air taxi, personal air vehicle, etc.) and ODAM port (covering vertiport, skyport, and airfield). Moreover, we propose the following ODAM operational research problems; while these problems interact with each other, they are listed in a chronological order.

3.1.1. ODAM Demand Estimation. Estimate the demand potential for ODAM operations in a given region. Traditional models, such as gravity or radiation model, are good for estimating the large demands. Accordingly, out of the box, these models have limited applicability since ODAM operations cannot be assumed to fully capture such estimates. ODAM, by design, is targeting special trips, often with lower demand (premium passengers, urgent transportation requests, or those without any reasonable transportation alternatives). Accordingly, there is a need for demand estimation including (a) uncertainty, (b) presence of existing transportation infrastructure, and (c) temporal information (time of day).

3.1.2. ODAM Port Location Problem. Optimize the locations of ODAM ports in a given region. This problem has to rely on accurate estimations from the previous stage (ODAM demand estimation). The optimization function for the ODAM port location problem cannot simply be transportation time or cost. Instead, this is naturally multiobjective: it needs to further include ground access time for passengers, environmental costs, and other societal costs.

3.1.3. ODAM Scheduling. Design schedules for ODAM taxis. Three types of problems are conceivable: first, a simple model where all ODAM taxis are grounded until there is a transportation request. In this case, there is no special need for scheduling between ODAM ports, second, a model where all ODAM taxis are airborne in anticipation of trip requests (as induced by ODAM demand estimation) in order to reduce air access time and maximize vehicle in-use time, and third, a model combining both previous models into a general one.

3.1.4. ODAM Dispatching. Assign actual trips to ODAM taxis. This case is specifically interesting for ODAM scheduling operations, where some ODAM taxis are grounded and others are in flight. Choosing an appropriate ODAM vehicle (or, in an extreme case, rejecting the transportation request) involves decisions regarding ODAM taxi capabilities, estimated profit, passenger perception, and more.

3.1.5. ODAM Routing. Assign actual routes to ODAM taxis. This includes trajectory planning and collision avoidance, all under safety considerations and within operational limits. This stage has potential interactions with ODAM dispatching, in case of in-flight, on-demand requests, which lead to changes in planned trajectories.

Future research studies should carefully distinguish ODAM operations from traditional airline scheduling. For example, in scheduled air transportation, flight rotations consist mainly of revenue-generating trips between airports, whereas commercial airlines often analyze aircraft scheduling and other related optimization issues one or more months in advance. The ODAM service features door-todoor travel patterns, resulting in much more dynamic and complex operations. In addition, nonrevenue trips due to repositioning flights must also be taken into account in planning to meet dynamic demand, an event that is more 
likely to be avoided in conventional scheduled air transport. Since the demand mechanisms for ODAM services are often short term, less predictable, and less reproducible, the existing conventional air transportation planning process for ODAM services must be adapted [44], taking into account different variants of delay [79] and disruptions [80]. Moreover, most studies in the literature so far focus on ODAM taxis with space for only one passenger. The first real business model directly linked to ODAM operation is therefore likely to be a single-seater model, covering the transport needs of a single person. As a direct extension, a variant is conceivable in which more than one passenger share an ODAM taxi for a flight on the same route and thus head for the same departure and destination airfield/station. The problem with such operations, however, is that there is a compromise between the passenger pickup and the demand situation (on-demandness): in order to maximize the load factor of an ODAM taxi, the operator is tempted to wait for further requests, while additional waiting times let the passengers lose the benefits of on-demand operation. This compromise and the possibility of rejecting unprofitable transport requests are largely unexplored in the ODAM literature and deserve further attention. In this context, the behavior, aspirations, and acceptance of passengers should also be examined in detail. Studies that formally define and verify such standard problem formulations in transportation, e.g., in terms of traffic assignment [81], facility location [82], and location routing [83], are among the most frequently cited papers in their fields.

\subsection{Creating Reference Benchmark Datasets for ODAM.} When formulating appropriate ODAM research problems, there is a need to evaluate and compare required solution techniques, design decisions, and heuristics. This implies that once such research problems are clear and standardized, it must be possible to understand the state of the art, which is much easier when the same terminology is used. Other research areas, for example, have benefited massively from the establishment of reference datasets. For example, the existence of small-scale databases such as CAB [84] in hub location research [85], the equivalent of vertiport location problems in ODAM research projects, led to fair performance evaluations among the exact solution techniques and is considered the indispensable gold standard for a whole range of hub location problem types. Although the network consists of only 25 nodes, it has advanced this area further as its optimal solutions are well known to the community and easily accessible at all times. Over time, the desire to solve even larger problems has led to the development of additional standard datasets of increasing size, e.g., Turkish postal system dataset [86] and Australian postal dataset [87].

A starting point for ODAM datasets is to build on existing ground transport datasets, which usually contain information about locations (often in zones) as well as distances and requirements between these locations. For example, Transportation Networks for Research [88] maintains a collection of such datasets for several regions of the world. Table 6 summarizes the network data for some selected datasets. It becomes evident that these networks cover a broad spectrum of regions and scales. Together with publicly available reference contracts and jointly agreed benchmark measures (gap, execution time, loss of profit, etc.), we expect that such and other benchmark datasets, such as [89], will further shift the boundaries of successful ODAM research.

Regarding the creation of reference datasets, approaches in the literature on simulated data should be combined with real-world data. We propose Guangzhou, China, as an excellent candidate for such reference benchmarks. Guangzhou is the capital of Guangdong Province in southern China. First of all, Guangzhou is at the heart of the Pearl River metropolitan area, one of the largest urban agglomerations in the world, with an urban population of approximately 15 million in the year 2018. While Guangzhou has a rather wellestablished public transportation infrastructure, with bus/ subway/taxi networks and the third largest airport in China, yet, induced by its tremendous travel demands, it faces regular grid locks along its highways, i.e., there is a strong need for novel transportation solutions. The government of Guangzhou and China are pushing towards modern technologies, which make the implementations/simulations of ODAM taxis much easier than in conservative regions, such as, for instance, Germany. Moreover, EHang, the Chinese autonomous aerial vehicle company, has tested its first ODAM taxi network in Guangzhou on August 9, 2019. With this pilot program, EHang will help the Guangzhou government to set up a command-and-control center and to build up basic infrastructures to support ODAM, and more flight routes and ODAM ports would be tested as well before the real commercial operations. This makes Guangzhou an excellent testbed for preliminary scientific studies and early prototypical implementation in practice.

3.3. Development of a Universal, Multimodal ODAM Transportation Competition/Cooperation Model. Previous studies on ODAM services preferably focus on a single urban/regional area and report on specific results. Especially because regions around the world have their own specifications, it is not clear how universal the results of such studies are and how general conclusions could be transferred to other regions. The aim should therefore be to derive a universal model that, for example, provides predictions about the competitiveness of ODAM services in the presence of a specific standardized transportation infrastructure. In this way, general findings can also be adapted to other regions. Also, the understanding of the infrastructure as multimodal is decisive for the interpretability and validity of the studies. In our review, we found that most studies assume that ODAM services will compete with only one mode, especially with cars. In reality, however, ODAM must compete with the sum of all transport options in a given study area, which includes a well-developed public transport infrastructure, novel means of transportation such as electric scooters, and high-speed alternatives such as high-speed rail in the regional case. Without taking into account all the facets of the available modalities, the significance of the study results is 
TABLE 6: An overview of selected transportation networks for ODAM research at https://github.com/bstabler/TransportationNetworks.

\begin{tabular}{lcccc}
\hline Network & Zones & Links & Nodes & Folder \\
\hline Anaheim & 38 & 914 & 416 & TransportationNetworks/tree/master/Anaheim \\
Austin & 7388 & 18961 & 7388 & TransportationNetworks/tree/master/Austin \\
Barcelona & 110 & 2522 & 1020 & TransportationNetworks/tree/master/Barcelona \\
Berlin Center & 865 & 28376 & 12981 & TransportationNetworks/tree/master/Berlin-Center \\
Birmingham, England & 898 & 33937 & 14639 & TransportationNetworks/tree/master/Birmingham-England \\
Chicago-sketch & 387 & 2950 & 933 & TransportationNetworks/tree/master/Chicago-Sketch \\
Chicago & 1790 & 39018 & 12982 & TransportationNetworks/tree/master/chicago-regional \\
Eastern Massachusetts & 74 & 258 & 74 & TransportationNetworks/tree/master/Eastern-Massachusetts \\
Gold Coast, Australia & 1068 & 11140 & 4807 & TransportationNetworks/tree/master/GoldCoast \\
Hessen-asymmetric & 245 & 6674 & 4660 & TransportationNetworks/tree/master/Hessen-Asymmetric \\
Philadelphia & 1525 & 40003 & 13389 & TransportationNetworks/tree/master/Philadelphia \\
Sydney, Australia & 3264 & 75379 & 33837 & TransportationNetworks/tree/master/Sydney \\
Terrassa-asymmetric & 55 & 3264 & 1609 & TransportationNetworks/tree/master/Terrassa-Asymmetric \\
Winnipeg & 147 & 2836 & 1052 & TransportationNetworks/tree/master/Winnipeg \\
\hline
\end{tabular}

TABLE 7: An overview of global data sources for ODAM research.

\begin{tabular}{|c|c|c|}
\hline Data & Organizations & Links \\
\hline \multirow{7}{*}{ Air transportation } & Official Airline Guide (OAG) & http://www.oag.com/ \\
\hline & International Civil Aviation Organization (ICAO) & http://www.icao.int/ \\
\hline & Airport Council International & http://www.airports.org/ \\
\hline & Sarbe Airport Data Intelligence & http://www.sabreairlinesolutions.com/ \\
\hline & Open Flights & http://openflights.org/ \\
\hline & Innovata Flight Schedules & http://www.innovata-llc.com/ \\
\hline & International Union of Railways (UIC) & http://www.uic.org/ \\
\hline \multirow[t]{2}{*}{ Railway transportation } & OpenRailwayMap & https://www.openrailwaymap.org/ \\
\hline & Railway Directory & http://www.railwaydirectory.net/ \\
\hline \multirow{2}{*}{ Road transportation } & OpenStreetMap & https://www.openstreetmap.org/ \\
\hline & Open Source Routing Machine & https://project-osrm.org/ \\
\hline \multirow{4}{*}{ Routing services } & Google Maps & https://maps.Google.com/ \\
\hline & Baidu Maps & https://map.baidu.com \\
\hline & Transitland & https://transit.land/ \\
\hline & GTFS Router & https://atfutures.github.io/gtfs-router/ \\
\hline \multirow{5}{*}{ Population/economic data } & Gridded Population of the World & $\begin{array}{l}\text { https://sedac.ciesin.columbia.edu/data/collection/gpw- } \\
\text { v4/ }\end{array}$ \\
\hline & World Bank Open Data & https://data.worldbank.org \\
\hline & UN World Population Prospects & https://population.un.org/wpp/ \\
\hline & International Monetary Fund & https://www.imf.org/en/data/ \\
\hline & Global Change Data Lab & https://global-change-data-lab.org/ \\
\hline
\end{tabular}

rather limited. While the results of such analysis are highly city-/region-specific, depending on its geography, there should be the goal of producing universal conclusions that can be easily transferred. Naturally, researchers have to target a tradeoff between being too specific and operationally too far from being applicable. Clustering similar regions is a starting point for this research.

One reason for limiting coverage in previous studies is that researchers often conduct studies in regions for which data are available. However, given the recent progress in Open/Linked Data, there is an abundance of data. More importantly, organizations, researchers, and volunteers around the world have made enormous efforts to make data available at the planetary level [90, 91]. A few examples of such datasets are shown in Table 7 , covering a wide range of transport modes, routing services, and economic data. With these data, it is possible to consistently compare the potential of ODAM services across the planet and identify commonalities and dissimilarities, with the ultimate target of a universal multimodal transportation model that makes ODAM competition accessible.

\section{Conclusions}

The focus of our review is on the operational issues of ODAM. A large number of studies have appeared in the literature addressing this topic; our survey concerns a total of 100 references published in recent years. While there are several other issues in ODAM, e.g., vehicle design or propulsion system, there exist excellent reviews in these areas, e.g., on vehicle design [15], current technology for electronic VTOL drones [16], and propulsion technology [17]. We believe that our work on the operational issues in ODAM complements these existing reviews, helps to advance the 
understanding of ODAM, and paves the way towards its successful implementation.

Eventually, the three research challenges mentioned above lead to the overarching goal of research reproducibility. With existing, well-defined reference benchmarks and the availability of large amounts of data, it would be possible to reproduce and understand results from previous studies. A crucial prerequisite for this would be that authors make their additional data and codes available to the public as has become common in other areas in recent years, e.g., health care [92], geography [93], public sector [94], and education [95]. The Open Science Initiative [96] also calls for such an approach by making scientific data collected directly as part of an experiment or indirectly as a byproduct of a downstream analysis available to the public and online [97]. In addition to objective reproducibility, the provision of research data also benefits the overall effectiveness of scientific processes [98-101], which, for instance, also results in a robust citation advantage [102].

In addition to pure access to raw data, future projects in the field of ODAM research should be commonly planned, coordinated, and carried out. This also implies the willingness to make more in-depth findings and analyses accessible, as well as voluntary support for subsequent projects. One possibility for this is, for example, the establishment and founding of interest and working groups, which are committed to the ongoing observance of these requirements and whose members are representatives of various research institutions from different countries. At central conventions, conferences, and association meetings, essential progress should be recorded and evaluated so that work steps based on this can be derived. We are therefore committed to removing barriers to the availability and reusability of scientific data, codes, and study results used throughout ODAM research. This is crucial for reliable and long-term decisions about our future multimodal transport systems.

\section{Data Availability}

No data were used as the input for this review. The data as reported from other studies are subject to availability in the data tables and original publications.

\section{Conflicts of Interest}

The authors declare that they have no conflicts of interest.

\section{Acknowledgments}

This study was supported by the National Natural Science Foundation of China (Grant nos. 61861136005, 61851110763, and 71731001).

\section{References}

[1] H. Wen, J. Sun, and X. Zhang, "Study on traffic congestion patterns of large city in China taking beijing as an example," Procedia-Social and Behavioral Sciences, vol. 138, pp. 482491, 2014.
[2] A. Anas and G. R. Timilsina, Impacts of Policy Instruments to Reduce Congestion and Emissions from Urban Transportation: The Case of Sao Paulo, Brazil, The World Bank, Washington, DC, USA, 2009.

[3] R. Arnott and K. Small, "The economics of traffic congestion," American Scientist, vol. 82, no. 5, pp. 446-455, 1994.

[4] B. J. Holmes, M. H. Durham, and S. E. Tarry, "Small aircraft transportation system concept and technologies," Journal of Aircraft, vol. 41, no. 1, pp. 26-35, 2004.

[5] J. Schippl, M. Decker, and T. Fleischer, "Personal air vehicles as a new option for commuting in europe: vision or illusion?" in Proceedings of the 41st European Transport Conference (ETC 2013), Frankfurt, Germany, September 2013.

[6] B. J. Holmes, "A vision and opportunity for transformation of on-demand air mobility," in Proceedings of the 16th AIAA Aviation Technology, Integration, and Operations Conference, AIAA AVIATION Forum, Atlanta, GA, USA, June 2016.

[7] J. Holden and N. Goel, "Fast-forwarding to a future of ondemand urban air transportation," Tech. Rep., Uber Elevate, San Francisco, CA, USA, 2016.

[8] U Elevate, The Future of Urban Mobility, U Elevate, San Francisco, CA, USA, 2019, https://www.uber.com/in/en/ elevate/.

[9] Lilium, Lilium Webpage, 2019, https://lilium.com/.

[10] Kittyhawk, Kittyhawk Webpage, 2019, https://kittyhawk. aero/.

[11] Airbus, My Kind of Flyover, 2019, https://www.airbus.com/ newsroom/news/en/2016/12/My-Kind-Of-Flyover.html.

[12] R. W. T. H. Aachen, Silent Air Taxi, 2019, https://airspaceaachen.de/.

[13] X. Sun, S. Wandelt, and A. Zhang, "How did covid-19 impact air transportation? a first peek through the lens of complex networks," Journal of Air Transport Management, vol. 89, Article ID 101928, 2020.

[14] X. Sun, S. Wandelt, and A. Zhang, "Dissection of a singularity: the impact of covid-19 on aviation," Journal of International Logistics and Trade, vol. 18, no. 3, pp. 113-125, 2020.

[15] E. Stumpf, M. Kreimeier, P. Strathoff, J.-M. Lueckhof, and K.-U. Schroeder, "Small aircraft concept for regional ondemand air mobility," in Proceedings of the 31st ICAS Congress, Belo Horizonte, Brazil, September 2018.

[16] N. Polaczyk, E. Trombino, P. Wei, and M. Mitici, "A review of current technology and research in urban on-demand air mobility applications," in Proceedings of the Vertical Flight Society Autonomous VTOL Technical Meetings and Electronic VTOL Symposium, Mesa, Arizona, January 2019.

[17] H. D. Kim, A. T. Perry, and P. J. Ansell, "A review of distributed electric propulsion concepts for air vehicle technology," in Proceedings of the 2018 AIAA/IEEE Electric Aircraft Technologies Symposium (EATS), pp. 1-21, IEEE, Cincinnati, OH, USA, July 2018.

[18] M. Fu, R. Rothfeld, and C. Antoniou, "Exploring preferences for transportation modes in an urban air mobility environment: munich case study," Transportation Research Record, vol. 2673, no. 10, pp. 427-442, Article ID $0361198119843858,2018$.

[19] M. Decker, T. Fleischer, S. Meyer-Soylu, and S. Jens, "Personal air vehicles as a new option for commuting in Europe: vision or illusion," in Proceedings of the European Transport Conference, pp. 1-20, Frankfurt, Germany, October 2013.

[20] S. Rajendran and J. Zack, "Insights on strategic air taxi network infrastructure locations using an iterative constrained clustering approach," Transportation Research Part 
E: Logistics and Transportation Review, vol. 128, pp. 470-505, 2019.

[21] N. Syed, M. Rye, M. Ade et al., "Preliminary considerations for odm air traffic management based on analysis of commuter passenger demand and travel patterns for the silicon valley region of California," in Proceedings of the 17th AIAA Aviation Technology, Integration, and Operations Conference, p. 3082, Virginia Beach, VA, USA, June 2017.

[22] R. Binder, L. A. Garrow, B. German, P. Mokhtarian, M. Daskilewicz, and T. H. Douthat, "If you fly it, will commuters come? a survey to model demand for evtol urban air trips," in Proceedings of the 2018 Aviation Technology, Integration, and Operations Conference, p. 2882, Los Angeles, CA, USA, June 2018.

[23] L. A. Garrow, M. Ilbeigi, and Z. Chen, "Forecasting demand for on demand mobility," in Proceedings of the 17th AIAA Aviation Technology, Integration, and Operations Conference, p. 3280, Washington, DC, USA, June 2017.

[24] L. A. Garrow, B. German, P. Mokhtarian, and J. Glodek, "A survey to model demand for evtol urban air trips and competition with autonomous ground vehicles," in Proceedings of the AIAA Aviation 2019 Forum, p. 2871, Indianapolis, Indiana, June 2019.

[25] M. Kreimeier, P. Strathoff, D. Gottschalk, and E. Stumpf, "Economic assessment of air mobility on-demand concepts," Journal of Air Transportation, vol. 26, no. 1, pp. 23-36, 2018.

[26] J. C. Smith, J. K. Viken, N. M. Guerreiro et al., "Projected demand and potential impacts to the national airspace system of autonomous, electric, on-demand small aircraft," in Proceedings of the 12th AIAA Aviation Technology, Integration, and Operations (ATIO) Conference and 14th AIAA/ ISSM, Indianapolis, Indiana, September 2012.

[27] M. Mane and W. Crossley, "An approach to predict impact of demand acceptance on air taxi operations," in Proceedings of the7th AIAA Aviation Technology, Integration, and Operations Conference, Virginia Beach, VA, USA, September 2007.

[28] M. Kreimeier, A. Mondorf, and E. Stumpf, "Market volume estimation of thin-haul On-Demand Air Mobility services in Germany," in Proceedings of the 17th AIAA Aviation Technology, Integration, and Operations Conference, AIAA AVIATION Forum, Washington DC, USA, June 2017.

[29] M. Balac, A. R. Vetrella, R. Rothfeld, and B. Schmid, "Demand estimation for aerial vehicles in urban settings," IEEE Intelligent Transportation Systems Magazine, vol. 11, no. 3, pp. 105-116, 2019.

[30] H. Baik, A. A. Trani, N. Hinze, H. Swingle, S. Ashiabor, and A. Seshadri, "Forecasting model for air taxi, commercial airline, and automobile demand in the United States," Transportation Research Record: Journal of the Transportation Research Board, vol. 2052, no. 1, pp. 9-20, 2008.

[31] K. Becker, I. Terekhov, and V. Gollnick, "A global gravity model for air passenger demand between city pairs and future interurban air mobility markets identification," in Proceedings of the 2018 Aviation Technology, Integration, and Operations Conference, p. 2885, Los Angeles, CA, USA, June 2018.

[32] J. N. Robinson, M.-D. R. Sokollek, C. Y. Justin, and D. N. Mavris, "Development of a methodology for parametric analysis of STOL airpark geo-density," in Proceedings of the Aviation Technology, Integration, and Operations Conference, Los Angeles, CA, USA, June 2018.

[33] L. A. Somers, C. Y. Justin, and D. N. Mavris, "Wind and obstacles impact on airpark placement for STOL-based sub- urban air mobility," in Proceedings of the AIAA Aviation 2019 Forum, p. 3121, Indianapolis, Indiana, June 2019.

[34] P. D. Vascik and R. J. Hansman, "Development of vertiport capacity envelopes and analysis of their sensitivity to topological and operational factors," in Proceedings of the AIAA Scitech 2019 Forum, Article ID 0526, San Diego, CA, USA, January 2019.

[35] E. Lim and H. Hwang, "The selection of vertiport location for on-demand mobility and its application to seoul metro area," International Journal of Aeronautical and Space Sciences, vol. 20, no. 1, pp. 260-272, 2019.

[36] S. Rath and J. Y. Chow, "Air taxi skyport location problem for airport access,” 2019, https://arxiv.org/abs/1904.01497.

[37] B. German, M. Daskilewicz, T. K. Hamilton, and M. M. Warren, "Cargo delivery in by passenger evtol aircraft: a case study in the san francisco bay area," in Proceedings of the 2018 AIAA Aerospace Sciences Meeting, p. 2006, Kissimmee, FL, USA, January 2018.

[38] M. Daskilewicz, B. German, M. Warren, L. A. Garrow, S.-S. Boddupalli, and T. H. Douthat, "Progress in vertiport placement and estimating aircraft range requirements for evtol daily commuting," in Proceedings of the 2018 Aviation Technology, Integration, and Operations Conference, p. 2884, Los Angeles, CA, USA, June 2018.

[39] J. F. Campbell and M. E. O'Kelly, "Twenty-five years of hub location research," Transportation Science, vol. 46, no. 2, pp. 153-169, 2012.

[40] R. Z. Farahani, M. Hekmatfar, A. B. Arabani, and E. Nikbakhsh, "Hub location problems: a review of models, classification, solution techniques, and applications," Computers \& Industrial Engineering, vol. 64, no. 4, pp. 1096-1109, 2013.

[41] W. Dai, J. Zhang, and X. Sun, "On solving multi-commodity flow problems: an experimental evaluation," Chinese Journal of Aeronautics, vol. 30, no. 4, p. 1481, 2017.

[42] X. Sun, W. Dai, Y. Zhang, and S. Wandelt, "Finding p-hub median locations: an empirical study on problems and solution techniques," Journal of Advanced Transportation, vol. 2017, Article ID 9387302, 2017.

[43] G. Wawrzyniak, L. Millard, and D. A. DeLaurentis, "Analysis of network topologies for on-demand, intra-theater air mobility command operations," in Proceedings of the 9th AIAA Aviation Technology, Integration, and Operations Conference, Denver, CO, USA, June 2009.

[44] F. Van der Zwan, K. Wils, and S. Ghijs, Development of an Aircraft Routing System for an Air Taxi OperatorAeronautics and Astronautics, InTech, Chennai, India, 2011.

[45] L. W. Kohlman and M. D. Patterson, "System-level urban air mobility transportation modeling and determination of energy-related constraints," in Proceedings of the 2018 Aviation Technology, Integration, and Operations Conference, p. 3677, Los Angeles, CA, USA, June 2018.

[46] M. Mane and W. A. Crossley, "Allocation and design of aircraft for on-demand air transportation with uncertain operations," Journal of Aircraft, vol. 49, no. 1, pp. 141-150, 2012.

[47] K. Fagerholt, B. A. Foss, and O. J. Horgen, "A decision support model for establishing an air taxi service: a case study," Journal of The Operational Research Society, vol. 60, no. 9, pp. 1173-1182, 2009.

[48] B. de Jong, Optimizing Cost Effectiveness and Flexibility of Air Taxis, Master's thesis, University of Twente, Enschede, Netherlands, 2007. 
[49] D. W. Lee, E. J. Bass, S. D. Patek, and J. A. Boyd, "A traffic engineering model for air taxi services," Transportation Research Part E: Logistics and Transportation Review, vol. 44, no. 6, pp. 1139-1161, 2008.

[50] P. A. Bonnefoy, "Simulating air taxi networks," in Proceedings of the 37th Conference on Winter Simulation, pp. 1586-1595, Orlando, FL, USA, December 2005.

[51] S. A. M. Shihab, P. Wei, D. S. J. Ramirez, R. Mesa-Arango, and C. Bloebaum, "By schedule or on demand?-a hybrid operation concept for urban air mobility," in Proceedings of the AIAA Aviation 2019 Forum, p. 3522, Indianapolis, Indiana, August 2019.

[52] R. Rothfeld, M. Balac, K. O. Ploetner, and C. Antoniou, "Agent-based simulation of urban air mobility," in Proceedings of the 2018 Modeling and Simulation Technologies Conference, p. 3891, Sydney, Australia, January 2018.

[53] I. C. Kleinbekman, M. A. Mitici, and P. Wei, "eVTOL arrival sequencing and scheduling for on-demand urban air mobility," in Proceedings of the 2018 IEEE/AIAA 37th Digital Avionics Systems Conference (DASC), pp. 1-7, IEEE, London, UK, September2018.

[54] M. Bazargan, Airline Operations and Scheduling, Ashgate Publishing Limited, Farnham, UK, 2010.

[55] D. Ronen, "Scheduling charter aircraft," Journal of the Operational Research Society, vol. 51, no. 3, pp. 258-262, 2000.

[56] D. Kim and C. Barnhart, "Flight schedule design for a charter airline," Computers \& Operations Research, vol. 34, no. 6, pp. 1516-1531, 2007.

[57] C. A. Hane, C. Barnhart, E. L. Johnson, R. E. Marsten, G. L. Nemhauser, and G. Sigismondi, "The fleet assignment problem: solving a large-scale integer program," Mathematical Programming, vol. 70, no. 1-3, pp. 211-232, 1995.

[58] C. Barnhart, A. M. Cohn, E. L. Johnson, D. Klabjan, G. L. Nemhauser, and P. H. Vance, Airline Crew Scheduling, in: Handbook of Transportation Science, pp. 517-560, Springer, Berlin, Germany, 2003.

[59] C. Barnhart, N. L. Boland, L. W. Clarke, E. L. Johnson, G. L. Nemhauser, and R. G. Shenoi, "Flight string models for aircraft fleeting and routing," Transportation Science, vol. 32, no. 3, pp. 208-220, 1998.

[60] Y. Yao, W. Zhao, O. Ergun, and E. Johnson, "Crew pairing and aircraft routing for on-demand aviation with time window," SSRN Electronic Journal, 2020.

[61] W. Yang, I. Z. Karaesmen, P. Keskinocak, and S. Tayur, "Aircraft and crew scheduling for fractional ownership programs," Annals of Operations Research, vol. 159, no. 1, pp. 415-431, 2008.

[62] W. Yang, I. Z. Karaesmen, and P. Keskinocak, "Managing uncertainty in on-demand air travel," Transportation Research Part E: Logistics and Transportation Review, vol. 46, no. 6, pp. 1169-1179, 2010.

[63] D. Espinoza, R. Garcia, M. Goycoolea, G. L. Nemhauser, and M. W. P. Savelsbergh, "Per-seat, on-demand air transportation part i: problem description and an integer multicommodity flow model," Transportation Science, vol. 42, no. 3, pp. 263-278, 2008.

[64] D. Espinoza, R. Garcia, M. Goycoolea, G. L. Nemhauser, and M. W. P. Savelsbergh, "Per-seat, on-demand air transportation part ii: parallel local search," Transportation Science, vol. 42, no. 3, pp. 279-291, 2008.

[65] J.-F. Cordeau, G. Laporte, J.-Y. Potvin, and M. W. P. Savelsbergh, "Chapter 7 transportation on demand," Transportation, vol. 14, pp. 429-466, 2007.
[66] R. T. Institute, "North Carolina fourth-tier air transportation market analysis," National Consortium for Department of Trasnportation Division of Aviation, Tech. Rep, Washington, DC, USA, 2002.

[67] W. B. Cotton and D. J. Wing, "Airborne trajectory management for urban air mobility," in Proceedings of the 2018 Aviation Technology, Integration, and Operations Conference, p. 3674, Los Angeles, CA, USA, June 2018.

[68] R. Rothfeld, M. Balac, K. O. Ploetner, and C. Antoniou, "Initial analysis of urban air mobility's transport performance in sioux falls," in Proceedings of the 2018 Aviation Technology, Integration, and Operations Conference, p. 2886, Los Angeles, CA, USA, June 2018.

[69] Y. Liu, M. Kreimeier, E. Stumpf, Y. Zhou, and H. Liu, "Overview of recent endeavors on personal aerial vehicles: a focus on the US and Europe led research activities," Progress in Aerospace Sciences, vol. 91, no. C, pp. 53-66, 2017.

[70] P. D. Vascik and R. J. Hansman, "Evaluation of key operational constraints affecting on-demand mobility for aviation in the Los Angeles Basin: ground infrastructure, air traffic control and noise," in Proceedings of the 17th AIAA Aviation Technology, Integration, and Operations Conference, Virginia Beach, VA, USA, September 2017.

[71] P. D. Vascik, R. J. Hansman, and N. S. Dunn, "Analysis of urban air mobility operational constraints," Journal of Air Transportation, vol. 26, no. 4, pp. 133-146, 2018.

[72] S. Verma, J. Keeler, T. E. Edwards, and V. Dulchinos, "Exploration of near term potential routes and procedures for urban air mobility," in Proceedings of the AIAA Aviation 2019 Forum, p. 3624, Dallas, TX, USA, June 2019.

[73] A. Straubinger and R. Raoul, "Identification of relevant aspects for personal air transport system integration in urban mobility modelling," in Proceedings of the 7th Transport Research Arena TRA, Vienna, Austria, UK, April 2018.

[74] A. Straubinger, E. T. Verhoef, and K. O. Plötner, Options for a Welfare Analysis of Urban Air MobilityITEA, Hongkong, China, 2018.

[75] L. Wei, C. Y. Justin, S. I. Briceno, and D. N. Mavris, "Doorto-door travel time comparative assessment for conventional transportation methods and short takeoff and landing on demand mobility concepts," in Proceedings of the 2018 Aviation Technology, Integration, and Operations Conference, p. 3055, Atlanta, GA, USA, June 2018.

[76] X. Sun, S. Wandelt, and E. Stumpf, "Competitiveness of ondemand air taxis regarding door-to-door travel time: a race through europe," Transportation Research Part E: Logistics and Transportation Review, vol. 119, pp. 1-18, 2018.

[77] P. Kopardekar, "Urban air mobility: initial reflections," Tech. rep., NASA Ames Research Center, Moffett Field, CA, United States, 2017.

[78] M. Kraenzler, M. Schmitt, and E. Stumpf, "Conceptual design study on electrical vertical take off and landing aircraft for urban air mobility applications," in Proceedings of the AIAA Aviation 2019 Forum, p. 3124, Dallas, TX, USA, June 2019.

[79] X. Sun, S. Wandelt, and A. Zhang, "Resilience of cities towards airport disruptions at global scale," Research in Transportation Business \& Management, vol. 34, Article ID 100452, 2020.

[80] M. Zanin, Y. Zhu, R. Yan, P. Dong, X. Sun, and S. Wandelt, "Characterization and prediction of air transport delays in China," Applied Sciences, vol. 10, no. 18, Article ID 6165, 2020. 
[81] M. Patriksson, The Traffic Assignment Problem: Models and Methods, Courier Dover Publications, Mineola, NY, USA, 2015.

[82] J. F. Campbell, "Integer programming formulations of discrete hub location problems," European Journal of Operational Research, vol. 72, no. 2, pp. 387-405, 1994.

[83] G. Ghiani and G. Laporte, "Location-routing problems," Opsearch, vol. 38, no. 2, pp. 151-159.

[84] M. E. O'Kelly, "A quadratic integer program for the location of interacting hub facilities," European Journal of Operational Research, vol. 32, no. 3, pp. 393-404, 1987.

[85] J. F. Campbell and M. E. O'Kelly, "Twenty-five years of hub location research," Transportation Science, vol. 46, no. 2, pp. 153-169, 2012.

[86] S. Çetiner, An Iterative Hub Location and Routing Problem for Postal Delivery Systems, Ph.D. thesis, Citeseer, Princeton, NJ, USA, 2003.

[87] A. T. Ernst and M. Krishnamoorthy, "Efficient algorithms for the uncapacitated single allocation p-hub median problem," Location Science, vol. 4, no. 3, pp. 139-154, 1996.

[88] Transportation Networks for Research Core Team, Transportation Networks for Research, Transportation Networks for Research Core Team, 2019, https://github.com/bstabler/ TransportationNetworks.

[89] Public Transit Networks for Research, Transit Network Design Instances for Research, Public Transit Networks for Research, 2019, https://github.com/RenatoArbex/ TransitNetworkDesign.

[90] X. Sun, S. Wandelt, M. Hansen, and A. Li, "Multiple airport regions based on inter-airport temporal distances," Transportation Research Part E: Logistics and Transportation Review, vol. 101, pp. 84-98, 2017.

[91] S. Wandelt, Z. Wang, and X. Sun, "Worldwide railway skeleton network: extraction methodology and preliminary analysis," Institute of Electrical and Electronics Engineers Transactions on Intelligent Transportation Systems, vol. 18, no. 8, pp. 2206-2216, 2016.

[92] 1000 Genomes Project Consortium, "A map of human genome variation from population-scale sequencing," Nature, vol. 467, no. 7319, pp. 1061-1073, 2010.

[93] M. Haklay and P. Weber, "OpenStreetMap: user-generated street maps," Institute of Electrical and Electronics Engineers Pervasive Computing, vol. 7, no. 4, pp. 12-18, 2008.

[94] J. Hendler, J. Holm, C. Musialek, and G. Thomas, "US government linked open data: semantic.data.gov," Institute of Electrical and Electronics Engineers Intelligent Systems, vol. 27, no. 3, pp. 25-31, 2012.

[95] K. R. Koedinger, R. S. Baker, K. Cunningham, A. Skogsholm, B. Leber, and J. Stamper, A Data Repository for the EDM Community: The PSLC DataShop, Handbook of Educational Data Mining 43, CRC Press, Boca Raton, FL, USA, 2011.

[96] D. Partha and P. A. David, "Toward a new economics of science," Research Policy, vol. 23, no. 5, pp. 487-521, 1994.

[97] T. J. Vision, "Open data and the social contract of scientific publishing," BioScience, vol. 60, no. 5, pp. 330-331, 2010.

[98] P. N. Schofield, T. Bubela, T. Bubela et al., "Post-publication sharing of data and tools," Nature, vol. 461, no. 7261, pp. 171-173, 2009.

[99] S.-A. Sansone, P. Rocca-Serra, D. Field et al., "Toward interoperable bioscience data," Nature Genetics, vol. 44, no. 2, pp. 121-126, 2012.

[100] B. A. Nosek, J. R. Spies, and M. Moty, "Scientific utopia," Perspectives on Psychological Science, vol. 7, no. 6, pp. 615631, 2012.
[101] J. C. Molloy, "The open knowledge foundation: open data means better science," PLoS Biology, vol. 9, no. 12, p. e1001195, Article ID e1001195, 2011.

[102] H. A. Piwowar and T. J. Vision, "Data reuse and the open data citation advantage," PeerJ, vol. 1, p. e175, 2013. 